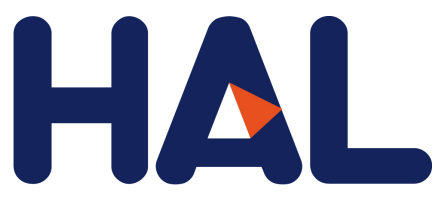

archives-ouvertes

\title{
Strain relaxation in He implanted UO 2 polycrystals under thermal treatment: an in-situ XRD study
}

J. Raynal, H. Palancher, R. Kachnaoui, A. Richard, J.-C. Richaud, C. Onofri, Alexandre Boulle, H. Rouquette, G. Martin, C. Sabathier, et al.

\section{- To cite this version:}

J. Raynal, H. Palancher, R. Kachnaoui, A. Richard, J.-C. Richaud, et al.. Strain relaxation in He implanted UO 2 polycrystals under thermal treatment: an in-situ XRD study. Journal of Nuclear Materials, Elsevier, 2016, 476, pp.63-76. 10.1016/j.jnucmat.2016.04.023 hal-02193222

\section{HAL Id: hal-02193222 \\ https://hal.archives-ouvertes.fr/hal-02193222}

Submitted on 24 Jul 2019

HAL is a multi-disciplinary open access archive for the deposit and dissemination of scientific research documents, whether they are published or not. The documents may come from teaching and research institutions in France or abroad, or from public or private research centers.
L'archive ouverte pluridisciplinaire HAL, est destinée au dépôt et à la diffusion de documents scientifiques de niveau recherche, publiés ou non, émanant des établissements d'enseignement et de recherche français ou étrangers, des laboratoires publics ou privés. 
Strain relaxation in $\mathrm{He}$ implanted $\mathrm{UO}_{2}$ polycrystals under thermal treatment: an in-situ XRD study.

J. Raynal, H. Palancher ${ }^{A^{*}}$, R. Kachnaoui ${ }^{A}$, A. Richard ${ }^{A, B}$, J-C. Richaud ${ }^{A}$, C. Onofri ${ }^{A}, A$.

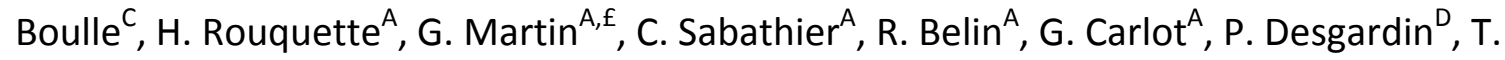
Sauvage $^{\text {D, F. Rieutord }}{ }^{\mathrm{E}}$, Ph. Goudeau ${ }^{\mathrm{B}}$, A. Ambard ${ }^{\mathrm{F}}$

${ }^{A}$ CEA, DEN, DEC, F-13108 St. Paul Lez Durance Cedex, France

${ }^{B}$ Institut Pprime, SP2MI, 86360 Chasseneuil, France

${ }^{c}$ SPCTS, CNRS, Limoges France

${ }^{D}$ CNRS-CEMHTI, UPR3079, 45071 Orléans, France

${ }^{E}$ CEA, DSM, INAC, 38000 Grenoble France

${ }^{F}$ EDF, R\&D Division, Les Renardières, 77818 Morez-sur-Loing, France

*Corresponding author: E-mail address: herve.palancher@cea.fr, Tel: +33 (0)4 42257555

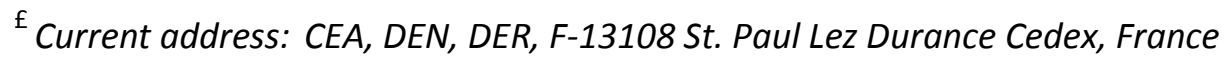




\begin{abstract}
Within the frame of the long-term evolution of spent nuclear fuel in dry disposal, the behavior of He in $\mathrm{UO}_{2}$ polycrystals has to be studied. In this paper, strain relaxation in He implanted samples have been characterized using in-situ X-ray diffraction during thermal annealing. The influence of a wide range of experimental parameters (annealing atmosphere, $\mathrm{He}$ ion energy, orientation of the $\mathrm{UO}_{2}$ grains probed by X-rays) has been evaluated. If each of them contributes to the strain relaxation kinetics in the implanted layer, strain relaxation is not completed for temperatures below $900{ }^{\circ} \mathrm{C}$ which is equivalent to what has been found on $\mathrm{He}$ implanted $\mathrm{UO}_{2}$ single crystals, or aged $\mathrm{UO}_{2}$ pellets doped with $\alpha$-emitters. This stands for an additional evidence of the interest of ion implantation to simulate self-irradiation in spent nuclear fuel. Moreover, in the case of implantation with $500 \mathrm{keV} \mathrm{He}$ ions, we clearly show that strain relaxation and He release are not correlated for temperatures below $750{ }^{\circ} \mathrm{C}$ and demonstrate that this applied in-situ approach is well-suited for measuring strains in ion implanted polycrystals.
\end{abstract}

Keywords: XRD, free swelling, alpha decay, Uranium dioxide, thermal recovery 


\section{Introduction}

The behavior of $\mathrm{He}$ in $\mathrm{UO}_{2}$ has been extensively analyzed mainly in the frame of long-term disposal of spent nuclear fuel, where helium is produced by the alpha-decay of actinides produced during in-pile irradiation [1]-[3]. Such studies have included many aspects: He behavior (lattice location [4], diffusion and precipitation [5]-[7][8]) but also created defect [9] and the induced strains in the $\mathrm{UO}_{2}$ matrix [10]. Different approaches have been used to produce relevant samples: aging of $\mathrm{UO}_{2}$ samples doped with short -lived $\alpha$-emitters [7][8][11]-[15], infusion [16], or ion implantation [1][5].

The alpha decay of actinides results in the production of both a recoil nucleus of about $100 \mathrm{keV}$ energy and a He particle (with energy ranging from 5.5 to $7 \mathrm{MeV}$ ). Ion implantation offers the opportunity to separate the contribution of both sources of damage (i.e. electronic or ballistic) [10][21] and to handle low activity samples. However, the quantitative characterization of strains in ion implanted polycrystals is not straightforward and from far less direct than in $\mathrm{UO}_{2}$ doped with short-lived $\alpha$-emitters. Indeed, because of the general difficulty to implant a $\mathrm{UO}_{2}$-based sample over its full thickness, measured strains have firstly to be interpreted using mechanical models [17][18] which take into account this specific geometry. Using this methodology, it is possible to derive a swelling in the implanted layer that is equivalent to that measured on samples doped with short lived $\alpha$-emitters [19]. Secondly in case of implantation using high energy He ions, the strain profile may not be constant over depth [20]. Finally, the chosen analytical technique has to enable a measurement of strains over the entire implanted layer. In other words, since the deepest part of the implanted layer exhibits the highest damage level, it has also to be probed. However, this is not systematically done because strain measurements are usually performed using Diffraction with X-rays (XRD) that must have an energy high enough to study buried layers in $\mathrm{UO}_{2}$ which strongly absorbs $\mathrm{X}$-rays.

The relaxation of strains has been analyzed in aged $\mathrm{PuO}_{2}$ [12], $\mathrm{MOX}$ [13], $\mathrm{U}_{0.8} \mathrm{Am}_{0.2} \mathrm{O}_{2-\mathrm{x}}$ [14] and even $(\mathrm{Pu}, \mathrm{Cm}) \mathrm{O}_{2}[15]$ showing that temperatures over $1100{ }^{\circ} \mathrm{C}$ are required to get a full strain recovery. As pointed out by Prieur et al., the obtained isochronal annealing curves are not only very close to each other but also close to that obtained for He implanted $\{111\}$ single crystals [14]. Note that Turcotte came to a similar conclusion when comparing self-irradiated $\mathrm{PuO}_{2}$ and $\mathrm{He}$ implanted $\mathrm{PuO}_{2}$ pressed pellets [21]. Strain relaxation has also been analyzed during isothermal annealings on He implanted $\mathrm{UO}_{2}$ polycrystals [22]. Under these conditions, strain relaxation generally consists of two steps: the first and shorter one (lasting about $5 \mathrm{~min}$ ) leads to the largest strain relaxation and is followed by a longer one (up to $10^{3} \mathrm{~min}$ ) with slower relaxation kinetics. However, very few data can be found in literature regarding strain relaxation in He implanted polycrystals under thermal annealing. One single work could be found in literature, but the author mentioned an over-oxidation of the analyzed sample which may have affected significantly the strain relaxation kinetics in the He implanted layer [23]. As a consequence, there is a need for an in-depth, rigorous reinvestigation of strain relaxation in He implanted $\mathrm{UO}_{2}$ polycrystals.

In this paper, the relaxation of strains induced by He ion implantation is studied by XRD mainly in-situ during thermal treatment but also ex-situ at room temperature. A wide range of experimental conditions is investigated; this includes different annealing types (iso-thermal or iso-chronal), conditions (temperature, durations) and atmospheres (vacuum, or $\mathrm{He} / \mathrm{H}_{2}$ ). Moreover these studies are performed on $\mathrm{UO}_{2}$ polycrystals implanted with two kinds of $\mathrm{He}$ ions: either $60 \mathrm{keV}{ }^{4} \mathrm{He}$ or $500 \mathrm{keV}$ 
${ }^{3} \mathrm{He}$ ions. The first ion energy offers the possibility to work on implanted layers with a well-defined mechanical behavior at room temperature and which present a simple in-depth strain profile [17][20][18]. The second ion energy has been chosen to enable a direct comparison of strain relaxation kinetics with He release kinetics [5][6]. Finally these strain relaxation kinetics will be compared to those measured in $\mathrm{He}$ implanted $\mathrm{UO}_{2}\{111\}$ single crystal [22] and self-irradiated $\mathrm{UO}_{2}$ samples.

\section{Experimental methods}

The crystallographic structure of fresh unstrained stoichiometric $\mathrm{UO}_{2}$ is well assessed at room temperature. It is a cubic fluorine like structure with $5.47 \AA$ lattice constant [24] and a Fm $\overline{3} \mathrm{~m}$ space group. The $\mathrm{UO}_{2}$ samples considered in this work are labelled $\mathrm{B} 1$ to $\mathrm{B} 6, \mathrm{X} 1$ to $\mathrm{X} 12$ and $\mathrm{Z} 1$ as shown in Table 1.

\section{a. Sample preparation and ion implantations}

Polycrystalline samples were initially cut from cylindrical pellets with $8 \mathrm{~mm}$ diameter into roughly 1 $\mathrm{mm}$ thick disks. They were subsequently annealed at $1700{ }^{\circ} \mathrm{C}$ for $24 \mathrm{~h}$ in a humidified flowing $\mathrm{Ar} / 5 \%$ $\mathrm{H}_{2}$ gas mixture $\left(\mathrm{H}_{2} \mathrm{O} / \mathrm{H}_{2}\right.$ ratio of $\left.1.7 \%\right)$. This guarantees that the stoichiometry of the samples was close to 2 . Samples were then polished with decreasing grain sizes. The last polishing stage involved a colloidal suspension known as OPU with circa $50 \mathrm{~nm}$ particle size. The average grain radius in the obtained $\mathrm{UO}_{2}$ disks was determined from optical microscopy at roughly $9 \mu \mathrm{m}$. Specimens were subsequently implanted at room temperature with He ions. One single sample has been implanted at the IPNL using $60 \mathrm{keV}{ }^{4} \mathrm{He}^{+}$ions up to a $10^{16} \mathrm{ion} / \mathrm{cm}^{2}$ final fluence. Sixteen additional polycrystals were implanted with $500 \mathrm{keV}^{3} \mathrm{He}^{+}$ions on the van de Graaff accelerator at CEMHTI (Orléans) to fluences of $10^{16}$ ions $/ \mathrm{cm}^{2}$. Among them, ten samples were especially prepared for this work whereas five disks were taken from another work i.e. already available [6]. The first of this last group is asimplanted, and the last four were further annealed at $750{ }^{\circ} \mathrm{C}$ during 4 hours, $800{ }^{\circ} \mathrm{C}$ during 4 hours, $1000{ }^{\circ} \mathrm{C}$ during $0.5 \mathrm{~h}$ and $1100{ }^{\circ} \mathrm{C}$ during $0.25 \mathrm{~h}$ respectively. Labels for these samples (i.e. B1, B2, B3, $\mathrm{B} 5, \mathrm{~B} 6)$ have been previously attributed [5]. Note that it has been checked that no surface flaking underwent as a result of the thermal annealing even if they were performed at high temperatures (above $1000^{\circ} \mathrm{C}$ ) [25].

For both implantation conditions, profiles of ion concentration and damages have been calculated with the SRIM software [26]. Displacement energies of 20 and $40 \mathrm{eV}$ for $\mathrm{O}$ and $\mathrm{U}$ atoms have been used [27]. As shown in Figure 1, the maximal damage values are 0.5 and $0.2 \mathrm{dpa}$ for $60 \mathrm{keV}{ }^{4} \mathrm{He}$ and $500 \mathrm{keV}^{3} \mathrm{He}$ ions respectively. Note that the thickness of the damaged layer (which is quite close to the strained one [20]) is about $0.3 \mu \mathrm{m}$ for $60 \mathrm{keV} \mathrm{He}$ implantations but much larger for $500 \mathrm{keV} \mathrm{He}$ ion implantation. 


\section{b. HR-XRD using synchrotron radiation}

$X$-ray diffraction measurements were performed on BM32 beamline (ESRF, Grenoble) using a parallel highly monochromatic $\left(\Delta E / E \approx 10^{-4}\right) X$-ray beam in the $\theta / 2 \theta$ geometry. These data collections were performed in single grains [20] of the X11 as-implanted He $500 \mathrm{keV}$ polycrystal using a $17 \mathrm{keV} X$-ray beam and a point detector (see Table 1 and section 2.c.iii for detailed sample description). Grains with four different orientations $(\{111\},\{200\},\{220\},\{311\})$ have been probed. The $X$-ray penetration depth in these grains with different out-of-plane orientations is not constant but is at least $3 \mu \mathrm{m}$ which significantly exceeds the thickness (about $1.3 \mu \mathrm{m}$ ) of the $500 \mathrm{keV}$ He implanted layer (see Figure 2 and section 2.c.i). As a consequence, a non-implanted (and therefore unstrained) part of this $\mathrm{UO}_{2}$ polycrystal has been systematically characterized. Figure 3-A shows these measurements; it has been chosen to plot the XRD data using $\Delta K / K_{0}$ values in abscissa where $K=2 \times \frac{\sin (\theta)}{\lambda}$ is the scattering vector magnitude and $\mathrm{K}_{0}$ is the values for each Bragg line for fresh unstrained $\mathrm{UO}_{2}$. Therefore $\Delta \mathrm{K} / \mathrm{K}_{0}$ values can be readily used to derive strains within the implanted layer.

\section{c. Laboratory XRD for ex-situ and in-situ measurements}

\section{i. XRD analyses}

For XRD measurements, two different setups were used. Both are based on a BRUKER D8 advance diffractometer equipped with a $\mathrm{Cu} \mathrm{X}$-ray source ( $\mathrm{Cu} \mathrm{K}_{\alpha 1}$ and $\mathrm{Cu} \mathrm{K}_{\alpha 2}$ radiations). Data were collected in the $\theta / \theta$ geometry using a Lynx Eye 1D solid state detector. For ex-situ measurements, the analyzed $\mathrm{UO}_{2}$ sintered disk was spinned around an axis perpendicular to its surface. The five sintered disks (labelled B1 to B6), taken from a previous work [5], were also analyzed with this setup. Note that these samples were only characterized after this isothermal annealing.

For XRD measurements during thermal annealing (referred to as HT-XRD in the present article), a setup dedicated to the XRD analysis in temperature of samples containing actinides (and therefore placed inside a glovebox) has been used [28]. For the characterization of bulk materials (i.e. not powders), the sample is placed onto an alumina sample holder and heated using a radiative Mo element. An MRI high temperature chamber has been used with two different conditions: vacuum $\left(2 \times 10^{-5}\right.$ mbar) or a flowing $\mathrm{He} / 5 \% \mathrm{H}_{2}$ gas mixture. Temperature was measured using a type $\mathrm{S}$ thermocouple placed a few hundred of micrometers above the sample surface (without contribution to the XRD pattern).

For each in-situ measurement, an XRD pattern has been collected at room temperature before and after each thermal treatment over a wide $2 \theta$ angular range. For non-ambient temperatures and because of the evolution with time of the sample (and therefore of the XRD patterns), only short data collections made sense: only few Bragg lines could be measured at each temperature step.

For such a symmetric data acquisition geometry, the X-ray penetration depth can be easily calculated provided that a criterion regarding the maximal absorption inside the material is defined. Here we assume that volumes located inside the sample cannot be probed if more than $90 \%$ of the X-ray beam intensity is lost by absorption inside the sample. Figure 2 indicates the maximum depth probed by 8 and $17 \mathrm{keV} \mathrm{X-rays} \mathrm{for} \mathrm{each} \mathrm{Bragg} \mathrm{line.} \mathrm{After} \mathrm{comparison} \mathrm{of} \mathrm{such} \mathrm{values} \mathrm{with} \mathrm{the} \mathrm{approximate} \mathrm{He}$ implanted layer thicknesses (for 60 and $500 \mathrm{keV}$ ), two conclusions can be drawn. First using $\mathrm{Cu} \mathrm{K}_{\alpha}$ 
radiations, X-rays are energetic enough to probe the non-implanted part of the sample implanted with $60 \mathrm{keV} \mathrm{He}$ ions for each Bragg line (even the ones occurring at the lowest $2 \theta$ angles). This will only be the case for Bragg lines measured at $2 \theta$ values higher than $40^{\circ}$ for the sample implanted with $500 \mathrm{keV}$. It has been checked experimentally that no contribution of the strain free substrate is observed for the $\{111\}$ and $\{200\}$ Bragg lines as opposed to the $\{220\}$ Bragg line (measured at $2 \theta$ values of about $47^{\circ}$ ). For strain measurements at different temperatures in such an anisotropic material [17], it is important to characterize Bragg lines with a contribution from the substrate which will be used as a (strain-free) reference for each temperature. For strain measurements, Bragg lines occurring at the highest $2 \theta$ values are usually selected since they provide a better accuracy: a larger $2 \theta$ difference between Bragg lines coming from the unstrained and the strained part of the sample is obtained. Therefore, $\{620\}$ is analyzed for samples implanted with $500 \mathrm{keV} H e$ ions. However, in the case of samples implanted with $60 \mathrm{keV}$ He ions, such high $2 \theta$ Bragg lines cannot be used because Bragg lines stemming from the implanted layer exhibit only very limited intensity with respect to background for low data acquisition times needed for in-situ analysis. This is a direct consequence of the very limited thickness of the $60 \mathrm{keV} \mathrm{He}$ implanted layer as compared to the X-ray penetration depth (see Figure 2). Finally, at least one of the following Bragg lines $(\{111\},\{200\},\{220\}$ or their harmonics) should be chosen in the set of Bragg line studied since the out-of-plane strain is in this case the only non-zero component of the strain tensor and is readily proportional to the linear free swelling induced by the ion implantation [19]. As a result of these requirements, $\{220\}$ and $\{311\}$ Bragg lines were selected for the $\mathrm{UO}_{2}$ disk implanted with $60 \mathrm{keV}$ He ions whereas $\{222\},\{440\}$ and $\{620\}$ were chosen for the analysis of samples implanted with $500 \mathrm{keV} H \mathrm{He}$ ions.

\section{ii. Temperature calibration}

Temperature has been calibrated under both annealing conditions used in this work: dynamic vacuum and $\mathrm{He} / 5 \% \mathrm{H}_{2}$ flowing gas. This was done into two steps. First the lattice constant evolution of a tungsten powder in the $\left[20 ; 1100{ }^{\circ} \mathrm{C}\right.$ ] temperature range [29] was measured. After this first temperature calibration, a second one has been performed using a fresh (non-implanted) $\mathrm{UO}_{2}$ sintered disk. The obtained temperature evolution of the lattice constant was compared to literature data [30]. An excellent agreement has been found under reducing atmosphere. For measurements performed under vacuum, a larger discrepancy has been found especially at low temperatures (below $300{ }^{\circ} \mathrm{C}$ ), although no significant oxidation of $\mathrm{UO}_{2}$ occurred during this isochronal thermal treatment up to $1000^{\circ} \mathrm{C}$. Indeed, firstly the $\mathrm{UO}_{2}$ lattice constants measured during the temperature increase are very close to those measured at the same temperature during the temperature decrease (better than $10^{-3} \AA$ ) . Furthermore, when comparing data measured before and after the thermal treatment, two observations can be made: no evolution of neither the $\mathrm{UO}_{2}$ lattice constant nor the width of $\mathrm{UO}_{2}$ Bragg line can be found and no additional peak with intensity significantly higher than background could be found in the pattern measured after the thermal treatment. Finally, for isochronal thermal treatments temperature stability was excellent since the $\mathrm{UO}_{2}$ lattice variation measured from the non-implanted substrate was smaller than $5 \times 10^{-4} \AA$.

To sum-up, temperature uncertainty has been evaluated to $\pm 10{ }^{\circ} \mathrm{C}$ under $\mathrm{He} / 5 \% \mathrm{H}_{2}$. Under vacuum, two values are considered: $\pm 50{ }^{\circ} \mathrm{C}$ for temperatures below $300{ }^{\circ} \mathrm{C}$ and $\pm 30{ }^{\circ} \mathrm{C}$ for higher temperatures. Reducing this temperature uncertainty will be the goal of future developments. 


\section{iii. Thermal treatment conditions}

Twelve $\mathrm{UO}_{2}$ polycrystals implanted with 60 and $500 \mathrm{keV}$ He ions were analyzed with in-situ HT-XRD. Concerning the samples implanted with $500 \mathrm{keV}{ }^{3} \mathrm{He}^{+}$ions, isochronal annealing under vacuum (sample X1) and reducing atmosphere (sample X9) were first performed up to 900 and $1000{ }^{\circ} \mathrm{C}$ respectively. For both annealings, the same temperature step $\left(50{ }^{\circ} \mathrm{C}\right)$ and holding times at each temperature were applied. Isochronal annealings on these $500 \mathrm{keV}{ }^{3} \mathrm{He}^{+}$ions implanted $\mathrm{UO}_{2}$ disks were only done under vacuum (samples X2 to X8, X10 and X12). Durations chosen for these isothermal thermal treatments are basically higher at low temperature than at high: they range from 0.5 up to 64 hours. Finally, samples coming from a previous work [5], and labelled B2 to B6 were annealed isothermally under vacuum at high temperatures (between 750 and $1100{ }^{\circ} \mathrm{C}$ ) during few hours or even less. Sample B1 has not been annealed and is kept as a reference.

A single $\mathrm{UO}_{2}$ polycrystal (Z1) implanted with $60 \mathrm{keV}$ He ions has been studied with in-situ HT-XRD. These measurements were performed under reducing atmosphere $\left(\mathrm{He} / 5 \% \mathrm{H}_{2}\right)$ at 13 different temperatures (up to $1100{ }^{\circ} \mathrm{C}$ ). For each temperature, successive "short" ( $3 \mathrm{~min}$ ) diffraction patterns were collected repeatedly in the vicinity of both the $\{220\}$ and the $\{311\}$ Bragg lines during an about 10000 seconds (i.e. about $167 \mathrm{~min}$ ) time period, before the acquisition of a longer (1 hour) one which was performed over a wide $2 \theta$ range. Such a data acquisition strategy should ensure that strains do not evolve significantly during the acquisition of the final pattern.

Table 1 gathers the annealing conditions for each $\mathrm{UO}_{2}$ polycrystal considered in this work.

\section{d. Data analysis}

XRD data were refined using the Rietveld method [31] and the FullProf software suite [32]; each Bragg line was analyzed independently from the others. Data measured during isochronal and isothermal annealing were analyzed manually and automatically [33] respectively. Indeed, since consecutive datasets may be very different in isochronal thermal treatment, it was not possible to analyze them automatically i.e. to prevent divergence of the least square procedure. Note that in the automatic refinement procedure, the refined values for a given pattern were used as input for the analysis of the next one.

The refined interatomic distances are post-treated to determine strains and strain relaxation. For each implanted sublayer ( 1 and 2 in 60 and $500 \mathrm{keV}$ He implanted $\mathrm{UO}_{2}$ samples respectively (see section 3.a)) and each analyzed temperature, the strain component normal to the sample surface can be readily determined. With this aim, the equation below is used:

$\varepsilon_{z Z}^{h k l}(T)=\ln \left(\frac{d_{d e}^{h l}(T)}{d_{0}^{h k l}(T)}\right) \approx \frac{d_{H e}^{h k l}(T)-d_{d}^{h k l}(T)}{d_{0}^{h k l}(T)}$.

Equation 1

where $d_{H e}^{h k l}(T)$ and $d_{0}^{h k l}(T)$ refer to the interatomic distances between $\{\mathrm{hkl}\}$ planes in $\{\mathrm{hkl}\}$ oriented grains in a given He implanted sublayer and in the strain free substrate respectively. The goal of this 


work is to study the strain relaxation which is defined by:
$\Delta \varepsilon_{Z Z}^{h k l}(T)=\frac{\varepsilon_{Z Z}^{h k l}(T)}{\varepsilon_{Z Z}^{h k l}\left(T_{a m b}\right)} \times 100$.

\section{Results}

\section{a. Mechanical model proposed for the implanted layer at room temperature}

\section{i. Implantation with $60 \mathrm{keV}{ }^{4} \mathrm{He}^{+}$ions}

For $\mathrm{UO}_{2}$ polycrystals implanted with $60 \mathrm{keV}$ He up to a limited fluence $\left(10^{16}\right.$ ion.cm $\left.{ }^{-2}\right)$, a wellestablished mechanical model is available [17][19]. It assumes that ion implantation induces an isotropic swelling which is prevented by the reaction of the non-implanted part of the sample considered as infinite. Indeed, this substrate cannot be deformed. Boundary conditions have been defined leading to the definition of a mechanical behavior law in the elastic regime. This model has been validated using micro XRD measurements. For three grain orientations ( $\{100\},\{110\},\{111\})$, the linear free swelling written $s / 3$ is a linear function of the measured out-of-plane strain [19]; its calculation is therefore straightforward provided that elastic constants are known:

$$
\begin{aligned}
& \frac{\mathbf{s}}{\mathbf{3}}=\frac{\mathrm{C}_{11}}{\mathrm{C}_{11}+2 \mathrm{C}_{12}} \times \boldsymbol{\varepsilon}_{z z}^{\mathbf{1 0 0}} \approx 0.65 \times \boldsymbol{\varepsilon}_{z z}^{\mathbf{1 0 0}} \\
& \frac{\mathbf{s}}{\mathbf{3}}=\frac{\mathrm{C}_{11}+\mathrm{C}_{12}+2 \mathrm{C}_{44}}{2\left(\mathrm{C}_{11}+2 \mathrm{C}_{12}\right)} \times \boldsymbol{\varepsilon}_{z z}^{\mathbf{1 1 0}} \approx 0.5 \times \boldsymbol{\varepsilon}_{z z}^{\mathbf{1 1 0}} \\
& \frac{\mathbf{s}}{\mathbf{3}}=\frac{\mathrm{C}_{11}+2 \mathrm{C}_{12}+4 \mathrm{C}_{44}}{3\left(\mathrm{C}_{11}+2 \mathrm{C}_{12}\right)} \times \boldsymbol{\varepsilon}_{z z}^{\mathbf{1 1 1}} \approx 0.46 \times \boldsymbol{\varepsilon}_{z z}^{\mathbf{1 1 1}}
\end{aligned}
$$

\section{Equation 3.A}

In the following, $\mathrm{C}_{11}, \mathrm{C}_{12}$ and $\mathrm{C}_{44}$ are taken as constant whatever the temperature and the irradiation conditions. Values provided by Fritz (i.e. 389, 119 and 60 GPa respectively) have been selected for this work [34]. Table 2 shows the linear swelling obtained by averaging strains measured for the three grain orientations $(\{100\},\{110\}$ and $\{111\})$. The obtained linear swelling values $(s / 3=0.46 \pm$ 0.01 ) for sample $\mathrm{Z1}$ are in excellent agreement with those measured in another $\mathrm{UO}_{2}$ polycrystal implanted in the same conditions $(s / 3=0.47 \pm 0.02)$ [19].

\section{ii. Implantation with $500 \mathrm{keV}{ }^{3} \mathrm{He}^{+}$ions}

To our best knowledge, no mechanical model has been proposed for thicker implanted layers, where the strain is not homogeneous along depth. XRD patterns measured in $\mathrm{UO}_{2}$ polycrystals implanted with $500 \mathrm{keV}{ }^{3} \mathrm{He}^{+}$ions, using laboratory diffractometers and monochromatic X-ray diffraction (see Figure 3), clearly show the presence of two sub-layers (i.e. with different $\varepsilon_{z z}$ strains) in the implanted layer. HR-XRD data collected using synchrotron radiations in the vicinity of the $\{220\}$ Bragg peak have been analyzed using the RADMAX software to provide both strain and structural disorder profiles [35][36]. To obtain reliable results, oscillations present in the HR-XRD data have to be accurately 
fitted (see section 2.c.i). Many combinations of strain and structural disorder profiles were tested. Two of them gave a satisfactory and similar agreement between measured and calculated HR-XRD data. The best solution has been selected using a unique reasonable hypothesis: the fitted structural disorder has to be higher in the deepest part (deeper than $0.6 \mu \mathrm{m}$ ) of the implanted layer in agreement with the higher damage values calculated in this area. Figure 4-A and -B show the soobtained $\varepsilon_{z z}$ strain profile and the comparison between measured and calculated HR-XRD patterns. The strain profile exhibits two plateaus at $0.9 \%$ and $0.58 \%$ which are attributed to layer $B$ and $A$ respectively in agreement with the qualitative interpretation of Figure $\mathbf{3}$ (see sections 2.b and 2.c.i). Moreover it can be seen in Figure 4-A that Layer A ranges from 0.2 to $0.4 \mu \mathrm{m}$ and layer B from 0.7 and $0.9 \mu \mathrm{m}$.

Finite element calculations have first demonstrated that in such a case, each sublayer exhibits an independent mechanical behavior from one another [18][37][38]. Therefore, linear free swelling is calculated for each sub-layer using Equations 3 as for the He $60 \mathrm{keV}$ implanted layer (with almost constant strains along depth). It is also assumed here that $\mathrm{UO}_{2}$ grains behave independently which is less appropriate than for polycrystals implanted with $60 \mathrm{keV}$ He ions [18][37][38]. For each $\mathrm{UO}_{2}$ polycrystal implanted with $500 \mathrm{keV}$ He ions considered in this work (and each sub-layer), Table 2 shows the measured $\boldsymbol{\varepsilon}_{z z}$ strain for grains oriented along $\{100\},\{110\}$ and $\{111\}$ and the associated linear free swelling. Because of the presence of additional peaks coming from the alumina sample holder which overlap with the $\{400\} \cup \mathrm{O}_{2}$ Bragg line, strains measured using this Bragg line are less accurate. This can also be seen in the higher values of standard deviation of $\boldsymbol{\varepsilon}_{z z}^{100}$ when averaged over all polycrystals (see Table 2). Whereas polycrystals X1 to X11 have been implanted in the same conditions, strains measured prior to any thermal treatment may fluctuate from one sample to another. To measure accurately strain relaxation, it is important to characterize samples in their asimplanted state at room temperature. This has not been possible for samples B2 to B6 (see section 2.c); the initial strains for these samples were taken identical to those measured on B1 (as they were implanted during the same campaign).

Finally it must be mentioned that other polycrystals implanted in the same conditions do not exhibit a clear presence of the sublayer $A$ in XRD patterns: the strain profile differs from the one shown in Figure 4. Within the frame of this work, they have been disregarded since at this time, no convincing explanation was raised to interpret this observation.

\section{b. Strain Relaxation kinetics}

\section{i. Isochronal thermal treatments}

\section{Behavior of polycrystal "Z1" under iso-chronal thermal treatment and a reducing atmosphere (He $60 \mathrm{keV}$ )}

Diffraction data measured in the vicinity of $\{220\}$ and $\{311\}$ Bragg lines during the thermal treatment performed under reducing atmosphere up to $1100{ }^{\circ} \mathrm{C}$ are shown in Figure 5. Again Bragg lines are doubled because of the $\mathrm{X}$-ray incoming beam which is made of two wavelengths, the two emission lines of copper ( $\mathrm{Cu} \mathrm{K} \mathrm{K}_{\alpha 1}$ and $\mathrm{Cu} \mathrm{K}_{\alpha 2}$ ). At room temperature, two couples of Bragg lines can be seen: the first couple is associated with the strained implanted layer whereas the second comes from the nonimplanted substrate. For $\{220\}$, these lines occur first at 46.5 and $46.6^{\circ}$ and then at about 47.0 and $47.1^{\circ}(2 \theta)$. With increasing temperature, Bragg lines coming from the unstrained substrate are shifted towards low diffraction angles as a result of lattice expansion. Moreover, the difference in 
diffraction angle between Bragg lines from the substrate and from the implanted layer decreases obviously. The images obtained for four Bragg lines $(\{111\},\{200\},\{220\}$ and $\{222\})$ show a plateau in strain recovery in the $\left[500 ; 600^{\circ} \mathrm{C}\right]$ temperature range which does not seem to be the case for $\{311\}$. In a first approximation, the strain recovery seems to be the fastest in the $\left[400 ; 500{ }^{\circ} \mathrm{C}\right]$ temperature range. Moreover for temperatures in the $\left[250 ; 500{ }^{\circ} \mathrm{C}\right]$ range, an additional contribution (with $\varepsilon_{z Z}^{220} \approx 0.3 \%$ ) can be observed at diffraction angles intermediate between strained and unstrained $\mathrm{UO}_{2}$ Bragg lines. This demonstrates an evolution in the in-depth strain profile (see section 4.b).

These data have been quantitatively analyzed, confirming the first qualitative presentation of strain recovery given above. Figure 6 shows the measured strains along the normal of the sample surface in the implanted layer for different times and temperatures (i.e. $\varepsilon_{z z}(T, t)$ ). Whatever the Bragg line, it can be observed that the kinetics of strain relaxation depend on temperature. Considering $\{220\}, \varepsilon_{z z}$ strain evolve very significantly at 400 and $500{ }^{\circ} \mathrm{C}$ by more than $0.09 \%$ (about $10 \%$ of the initial strain value) during the first $2500 \mathrm{~s}$. On the contrary, at 100, 200, 550, 600, 900, 1000 and $1100{ }^{\circ} \mathrm{C}$, these strains are almost constant taking into account error bars. Considering now $\{311\}$, strain relaxation kinetics are clearly different: if they are still high at $400{ }^{\circ} \mathrm{C}$ and limited below $300^{\circ} \mathrm{C}$, at $550^{\circ} \mathrm{C}, 1000$ and $1100{ }^{\circ} \mathrm{C}$, they are now very limited also at $500{ }^{\circ} \mathrm{C}$ and not negligible at $600{ }^{\circ} \mathrm{C}$. For $\{311\}$, theses strain relaxations appear to be steadier with temperature than for $\{220\}$. Note finally that the temperature increase from 900 to $1000{ }^{\circ} \mathrm{C}$, has a much higher influence on the strain relaxation measured with $\{311\}$ than with $\{220\}$.

Strains measured on five $(\{111\},\{200\},\{220\},\{222\}$ and $\{311\})$ Bragg lines at these 13 temperatures after almost 10000 seconds holding time can be compared as shown in Figure 7 . In this figure, strain recovery (i.e. $\left.\Delta \varepsilon_{z z}^{h k l}\right)$ ) instead of $\varepsilon_{z z}$ strain is plotted versus annealing temperature. In a first approximation, strain recovery measured from these five Bragg lines exhibit the same trend. A more quantitative approach shows some differences in particular in the $\left[400 ; 600{ }^{\circ} \mathrm{C}\right]$ temperature range: $\{311\}$ presents a behavior different from that observed for the four other Bragg lines ( $\{111\}$ (and obviously $\{222\}),\{200\},\{220\})$ which are very close. This suggests that, in this temperature range, the definition of a single free swelling value to describe the remaining consequences of $\mathrm{He} 60 \mathrm{keV}$ implantation is not rigorously accurate.

An estimation of the average strain relaxation with temperature for the $60 \mathrm{keV}$ He polycrystal has been tentatively calculated: these average values have been determined based on four crystallographic orientations ( $\{200\},\{220\},\{311\}$ and $\{222\})$ for each annealing temperature. Figure 8 shows these averaged values. Error bars indicate the associated minimal and maximal residual strains. This figure also shows a first derivative of this curve after fitting and smoothing with cubic splines [37]. The maximal strain relaxation rate occurs at $400^{\circ} \mathrm{C}$.

\section{Behavior of polycrystal "X9" under iso-chronal thermal treatment and a reducing atmosphere (He $500 \mathrm{keV}$ )}

The mechanical behavior of polycrystal $X 9$ has been studied in-situ using HT-XRD during an isochronal annealing under reducing atmosphere $\left(\mathrm{He} / 5 \% \mathrm{H}_{2}\right)$. Holding time at each temperature was about $350 \mathrm{~s}$ after temperature stabilization. Diffraction data collected during this analysis were restricted to the vicinity of the $\{222\}$ Bragg line. Figure 9-A shows the temperature evolution of this Bragg line during this thermal treatment. As described in Figure 3-B, the presence of three couples of Bragg lines can 
be seen at room temperature; they are associated with the non-implanted substrate and with the two components (written Layers $\mathrm{A}$ and $\mathrm{B}$ ) of the He implanted layer. At room temperature their angular position is $(58.4,58.6),(58.0,58.2)$ and $(57.8,58.0)$ respectively. As expected, the angular position of the Bragg lines associated with the implanted layer becomes closer to those related to the non-implanted part, the strongest variation happening for temperatures in the $\left[300 ; 400{ }^{\circ} \mathrm{C}\right]$ range. As in the previous experiment, strain recovery in this temperature range occurs at the same time as a modification of strain gradient profile (see section 4.b). For temperatures higher than $400{ }^{\circ} \mathrm{C}$, strain variation in the implanted layer seems to be limited. However above $800^{\circ} \mathrm{C}$, strains in layer $\mathrm{B}$ are more difficult to estimate since this layer is less easy to observe (lower intensity, broadening or overlap with layer A peaks).

Then this diffraction data were analyzed quantitatively using the Rietveld method. It has been chosen to use three different lattice constants to fit the implanted layer, except in the $\left[25 ; 250^{\circ} \mathrm{C}\right]$ temperature range. An additional layer, written $C$, is therefore considered (without however indication about its in-depth location) with strain values lower than in layer $A$. The measured $\varepsilon_{z Z}^{222}$ strains and strain recovery (i.e. $\Delta \varepsilon_{z Z}^{222}$ ) are shown in Figure 10-A and $-\mathrm{B}$ respectively. Three temperature ranges have to be considered. First, below $300{ }^{\circ} \mathrm{C}$, the strain recovery is limited as temperature increases. At $300{ }^{\circ} \mathrm{C}$, remaining strains in layers $\mathrm{A}$ and $\mathrm{B}$ are higher than $80 \%$, and the contribution of layer $\mathrm{C}$ is observed $(0.4 \%)$ for the first time. At $400{ }^{\circ} \mathrm{C}$, layer $\mathrm{A}$ strongly and sharply decreases followed by layer $B$ at a temperature higher by $50^{\circ} \mathrm{C}$. Then strain recovery in layers $\mathrm{A}$ and $B$ does not evolve significantly up to $850^{\circ} \mathrm{C}$, where the presence of layer $\mathrm{B}$ can be definitely assessed (because of a possible overlap with layer A Bragg peak). Strains in layer A keep on decreasing and remaining strain is close to $26 \%$ at $1000{ }^{\circ} \mathrm{C}$. At this temperature, strains in layer $\mathrm{C}$ are about $0.1 \%$. Strain recovery cannot be considered in layer $\mathrm{C}$ since it is not present at room temperature.

To conclude, it has been assessed with this study that strain recovery in layers A and B are similar for temperatures up to about $800^{\circ} \mathrm{C}$; for higher temperatures, the strain recovery in layer $A$ seems to be higher and the presence of layer $B$ could not be definitely demonstrated. Finally for temperatures above $300{ }^{\circ} \mathrm{C}$, the in-depth strain profile is modified (as compared to the one measured at room temperature).

\section{Behavior of polycrystal "X1" under iso-chronal thermal treatment (He $500 \mathrm{keV}$, vacuum)}

The study of strain relaxation in the implanted layer of the $X 1$ sample has been performed in the same conditions than $\mathrm{X} 9$, except the atmosphere: vacuum has been used in this case. Figure 9-B shows the data measured during this experiment in the vicinity of the $\{222\}$ Bragg line. Again it can be seen that (i) between 300 and $400{ }^{\circ} \mathrm{C}$ an accelerated strain relaxation occurs, (ii) this relaxation is not completed at $860^{\circ} \mathrm{C}$ and (iii) an additional Bragg peak coming from the implanted layer appears for temperatures in the $\left[400 ; 500^{\circ} \mathrm{C}\right]$ range.

These three observations are confirmed by Rietveld refinement. The results are given in Figure 11-A and $B$ - for strains and strain recovery respectively. First strain relaxation in layer $B$ is smoother than in layer $A$. If their strain recovery in both layers is identical for temperatures up to $450{ }^{\circ} \mathrm{C}$, strains in layer A decrease much more significantly in the $\left[450 ; 500{ }^{\circ} \mathrm{C}\right.$ ] temperature range. For higher temperatures, strain relaxation with temperatures remains similar in both layers. The existence of 
layer $A$ and $B$ is assessed up to 650 and $800{ }^{\circ} \mathrm{C}$ respectively. Indeed above $650{ }^{\circ} \mathrm{C}$, Bragg peaks associated with $A$ overlap significantly with those of the non-implanted substrate. Using the pattern collected after the annealing at room temperature over a wide $2 \theta$ angular range (and for example the $\{531\}$ Bragg line), the existence of remaining strains in layer $A$ has been confirmed.

\section{ii. Isothermal annealing: behavior of polycrystals "X2-X8","X10", "X12" and "B2-B6" under vacuum (He $500 \mathrm{keV}$ )}

The strain relaxation in the $\mathrm{He} 500 \mathrm{keV}$ implanted layer has been measured under vacuum on 9 samples for temperatures ranging from 180 to $870{ }^{\circ} \mathrm{C}$ and durations from 0.5 up to $64 \mathrm{~h}$. Results of the quantitative analysis (i.e. Rietveld refinement) is shown in Figure 12. Whatever the temperature, the obtained curves first show a faster strain relaxation (in the first $300 \mathrm{~s}$ ) and then a slower one. Strain relaxation kinetics are very close for each studied temperature except for $250{ }^{\circ} \mathrm{C}$, where layer $B$ strain recovery is much quicker. Even for the longest thermal treatment, strain recovery is incomplete. Strain recovery is generally larger for layer A than B for a given annealing duration and temperatures above $200{ }^{\circ} \mathrm{C}$. Below this threshold value, strain recovery is too low to conclude. For temperatures of $300^{\circ} \mathrm{C}$ or higher, this difference of residual strain equals to about $20 \%$.

As expected from the isochronal study (see section 3.b.i.3), strain profile variations have been observed during the isochronal study at $300{ }^{\circ} \mathrm{C}$. However, based on the collected data, it was not possible to characterize them. Finally for high temperatures (above $730^{\circ} \mathrm{C}$ ), microstructural changes in the implanted layer are twofold: not only strains decrease significantly but also a sort of recrystallization occurs. Here this recrystallization is associated with the increase in measured intensity for a given Bragg line during the isothermal annealing. This is shown by Figure 13 where the integral intensities of the $\{620\}$ Bragg line (from both the implanted layer and the substrate) measured at four different temperatures are compared. An increase in integral intensity is only observed during the isochronal annealing at 730 and $870^{\circ} \mathrm{C}$ but not at 180 and $620^{\circ} \mathrm{C}$.

The strain recovery measured during the isochronal annealing under vacuum of He implanted $\mathrm{UO}_{2}$ polycrystals can be compared to the values obtained after an isothermal annealing at the same temperatures (see Figure 14). The residual strains are systematically lower in the samples treated isothermally. This can be explained by the systematic longer holding time chosen here for an isothermal annealing than for an isochronal one (see Table 1). It must be mentioned that strain relaxation measured ex-situ at the end of thermal treatments in polycrystals B2 to B6 is also in a good agreement with the data measured by in-situ HT-XRD whereas annealing under vacuum were performed in different furnaces. Again, for these four samples, the $\varepsilon_{z z}$ values measured in the asimplanted B1 sample have been used to define the initial reference state which may be an additional (but limited) source of uncertainty.

\section{Discussion}

\section{a. Parameters influencing strain relaxation kinetics}

Three parameters influence the measured strain relaxation of a He implanted $\mathrm{UO}_{2}$ polycrystal. Firstly, strain relaxation presents some difference in the $\left[400 ; 900^{\circ} \mathrm{C}\right]$ temperature range depending on the 
Bragg line (i.e. grain orientation) which is considered. This means that at this step, an accurate strain relaxation associated with a given implanted $\mathrm{UO}_{2}$ polycrystal sample cannot be defined. Secondly, Figure 15-A shows that strain relaxation in two $\mathrm{UO}_{2}$ polycrystals implanted with He ions of $60 \mathrm{keV}$ and $500 \mathrm{keV}$ energy respectively is not strictly the same. Note that such a quantitative comparison is possible in this figure since in both cases (i) the strain relaxation is measured using the same $\{222\}$ Bragg line and (ii) the maximal strain in the implanted layer (e.g. layer B for the sample implanted with $500 \mathrm{keV} \mathrm{He}$ ions) is considered. Finally, it is clear that the atmosphere used for the thermal annealing has an influence on strain relaxation for temperatures above $200{ }^{\circ} \mathrm{C}$ (see Figure $15-\mathrm{B}$ ). This is especially true for layer $A$ which is more significantly relaxed under vacuum than under $\mathrm{He} / \mathrm{H}_{2}$ for temperatures higher than $500{ }^{\circ} \mathrm{C}$. Assuming that vacuum conditions induce a slight oxidation of the $\mathrm{UO}_{2}$ surface, the faster strain relaxation kinetics observed under vacuum could be explained. With a better description of the strain profile in the implanted layer for each temperature, we checked whether the closest layers from the sample surface exhibit accelerated strain relaxation in the sample annealed under vacuum. Eventually, note that strain evolution in the implanted layer is smoother under vacuum.

\section{b. In-depth strain profile variation during thermal annealing}

A modification of the in-depth strain profile has been clearly observed during thermal treatments for temperatures in the $\left[300 ; 500{ }^{\circ} \mathrm{C}\right]$ range especially under reducing atmosphere. This strain variation has been observed whatever the energy of the He ions used for implantation: additional Bragg lines are observed in the pattern measured at $300{ }^{\circ} \mathrm{C}$ on the $60 \mathrm{keV} \mathrm{He}$ implanted polycrystal (see Figure 16-B) and in the one measured at $350^{\circ} \mathrm{C}$ on the $500 \mathrm{keV}$ He implanted polycrystal (see Figure 16-A). For this last case, this additional Bragg line is associated to a "Layer C" in the implanted part. These Bragg lines have not been observed in the patterns measured at room temperature (see for example Figure 3).

\section{c. Strain relaxation versus temperature: comparison with literature data}

The characterization of strain relaxation with temperature has been reported for different $\mathrm{UO}_{2}$ based materials: $\mathrm{UO}_{2}$ poly and single crystals implanted with $\alpha$ particles [22][23], self-irradiated MOX [13], $\mathrm{U}_{0.8} \mathrm{Am}_{0.2} \mathrm{O}_{2-\mathrm{x}}$ [14] or $(\mathrm{Pu}, \mathrm{Cm}) \mathrm{O}_{2}$ pellets [15]. For a comparison of these results with the data presented in this paper, we propose to focus on the case of polycrystal Z1 (implanted with $60 \mathrm{keV} \mathrm{He}$ ions) which is the simplest mechanical system to analyze and for which the most robust conclusions regarding strain relaxation with temperature have been provided here.

Figure 17 shows this comparison for temperatures up to $1200{ }^{\circ} \mathrm{C}$. Even if those data have been obtained using different experimental conditions (annealing atmosphere, temperature ramp, holding times, XRD data collection strategies), a good qualitative agreement can be observed if the measurement done on $\mathrm{UO}_{2}$ polycrystal implanted with $5.5 \mathrm{MeV} \mathrm{He}$ ions is not considered. Indeed only in this last experiment, a full strain relaxation is complete at $600{ }^{\circ} \mathrm{C}$ whereas it is not the case at $1100{ }^{\circ} \mathrm{C}$ for other five experiments. This odd behavior for the $\mathrm{UO}_{2}$ polycrystal implanted with $5.5 \mathrm{MeV} \mathrm{He}$ is probably the consequence of an experimental problem (oxidation of the polycrystal) 
[23]. Therefore this measurement will not be considered in the subsequent part of this paper. As a consequence it seems that relaxation of strains stemming from He implantation or self-irradiation in single or polycrystals is identical at a first approximation. Turcotte came to a similar conclusion comparing the strain recovery for self-irradiated and $\alpha$ bombarded $\mathrm{PuO}_{2}$ polycrystals [21].

A more accurate analysis of Figure $\mathbf{1 7}$ shows that the strain relaxation measured on self-irradiated materials is smoother than data collected on $\mathrm{He}$ implanted $\mathrm{UO}_{2}$ materials (single or polycrystals). Indeed for this last type of materials, steps in strain relaxation are more visible. This suggests that in He implanted $\mathrm{UO}_{2}$ samples, a lower number of defect type is present. However these steps are found not strictly at the same temperature for both $\mathrm{He}$ implanted $\mathrm{UO}_{2}$ samples: plateaus are observed first between 300 and $500{ }^{\circ} \mathrm{C}$ and then between 600 and $800{ }^{\circ} \mathrm{C}$ on $\mathrm{UO}_{2}$ single crystal implanted with $\alpha$ particles, whereas only one (between 500 and $600^{\circ} \mathrm{C}$ ) can be seen in the annealing of the polycrystal implanted with $60 \mathrm{keV}$ He ions.

\section{d. Comparison of He release with strain relaxation- defect identification}

The He concentration in the implanted $\mathrm{UO}_{2}$ polycrystal has been measured after a thermal treatment under vacuum for samples B2 to B6 using nuclear reaction analysis [5][6]. Residual strains in these samples have been measured subsequently, allowing a comparison between kinetics of both strain relaxation and He release for temperatures below $1100{ }^{\circ} \mathrm{C}$ (see Figure 18). Firstly it appears that the higher the annealing temperature, the lower both the residual He concentration and the remaining strain. Secondly this comparison shows that at $750{ }^{\circ} \mathrm{C}$, a low fraction of the He has been released (less than $20 \%$ ) whereas most of strain is relaxed (more than $80 \%$ ). This means that for temperatures in the $\left[300 ; 750{ }^{\circ} \mathrm{C}\right]$ temperature range, the observed significant strain relaxation cannot be directly attributed to the He release: both phenomena are not correlated in this temperature range. As a consequence, the strains annealed below $750{ }^{\circ} \mathrm{C}$ are caused by defects very few associated with He atoms.

This confirms the validity of defect attributions done for each recovery stage observed during thermal annealing of $\mathrm{UO}_{2}$ based materials damaged by $\mathrm{He}$ particles (self-irradiation or ion implantation). This defect attribution is performed by comparing activation energies deduced from measurements (XRD [22], differential scanning calorimetry [7]) with modelling data from literature. With this approach the two first recovery stages evidenced at $\left[300 ; 400{ }^{\circ} \mathrm{C}\right]$ and at $\left[550 ; 600{ }^{\circ} \mathrm{C}\right]$ are attributed to the recombination of point defects ( $\mathrm{O}$ and $\mathrm{U}$ interstitials respectively) i.e. defects not related to He. Only for the third recovery stage (observed at higher temperature i.e. close to $900{ }^{\circ} \mathrm{C}$ ), the association of defects with He was proposed [22].

Beyond the association of these defects with He or not, the exact nature of the defects is still a matter of debate. Indeed, for temperatures in the $\left[300 ; 400{ }^{\circ} \mathrm{C}\right]$ range, positron annihilation spectroscopy measurements have suggested the presence of defects based on uranium vacancies or on complexes involving uranium vacancies [9]. Note finally that advances in the interpretation of Raman spectroscopy measurements in such samples would probably help to identify the nature of defect involved at the two first recovery stages. Indeed, with this technique, it has been shown on $\mathrm{UO}_{2}$ polycrystals implanted with $25 \mathrm{MeV} \mathrm{He}^{2+}$ ions [40], that a full recovery of the damage peaks is obtained for temperatures ranging from 525 up to $675{ }^{\circ} \mathrm{C}$ which is again not the case for XRD and 
DSC for example. In other words, Raman spectroscopy is not sensitive to the defects involving He atoms which are annealed at higher temperatures.

\section{Conclusion}

The behavior under thermal annealing of $\mathrm{He}$ implanted $\mathrm{UO}_{2}$ polycrystals has been analyzed using insitu XRD under various experimental conditions: vacuum, reducing atmosphere and different $\mathrm{He}$ ion energies. This enables to demonstrate firstly that no full recovery in the implanted layer is found for temperatures below $900{ }^{\circ} \mathrm{C}$ and secondly that strain relaxation and He release are two distinct mechanisms at a macroscopic scale. Thirdly strain relaxation in grains with different out-of-plane orientations in the same implanted $\mathrm{UO}_{2}$ polycrystal is not strictly identical and the strain profile evolves during annealing especially when a reducing atmosphere is selected. The use of in-situ XRD is extremely well adapted to the characterization of strain evolution in the implanted layer because both the implanted layer and the non-implanted substrate are probed simultaneously. This is not the case for example for the study of self-irradiated pellets since an additional correction for the thermal expansion of the damaged material has to be performed [14]. However this advantage may become a limitation in case of small deformations because Bragg lines from the substrate and the implanted layer may overlap. To overcome this problem and to access the strain profile within the implanted layer, the use of synchrotron radiation would be well suited. Another important prospect to this work could be the analysis of strains at grain boundaries [38][41] since He release is quicker there than in grain cores [5]. Finally it would be very interesting to compare the strain relaxation kinetics obtained here for He with those measured in case of implantation with fission product. Preliminary work within this frame has been initiated [42]. 


\section{References}

[1] C. Ferry, C. Poinssot, C. Cappelaere, L. Desgranges, C. Jegou, F. Miserque, J.P. Piron, D. Roudil, J.M. Gras, J. Nucl. Mater. 352 (2006) 246-253.

[2] C. Ferry, J-P Piron, A. Ambard, J. Nucl. Mater. 407 (2010) 100-109.

[3] T. Wiss, J-P. Hiernaut, D. Roudil, J-Y. Colle, E. Maugeri, Z. Talip, A. Janssen, V. Rondinella, R.J.M. Konings, H-J. Matzke, W. J. Weber, J. Nucl. Mater. 51 (2014) 198-206.

[4] T. Belhabib, P. Desgardin, T. Sauvage, H. Erramli, M.F. Barthe, F. Garrido, G. Carlot, L. Nowicki, P. Garcia, J. Nucl. Mater. 467 (2015) 1-8.

[5] P. Garcia, G. Martin, P. Desgardin, G. Carlot, T. Sauvage, C. Sabathier, E. Castelier, H. Khodja, M.-F. Barthe, J. Nucl. Mater. 430 (2012) 156-165.

[6] G. Martin, Ph.D. thesis, University of Orléans (2007).

[7] D. Staicu, T. Wiss, V.V. Rondinella, J.P. Hiernaut, R.J.M. Konings, C. Ronchi, J. Nucl. Mater. 397, (2010) 8-18.

[8] Z. Talip, T. Wiss, V. Di Marcello, A. Janssen, J.-Y. Colle, P. Van Uffelen, P. Raison, R.J.M. Konings, J. Nucl. Mater. 445 (2014) 117-127.

[9] H. Labrim, M.-F. Barthe, P. Desgardin, T. Sauvage, C. Corbel, G. Blondiaux, J. P. Piron, Nuclear Instruments and Methods in Physics Research B261 (2007) 883-887.

[10] W.J. Weber, J. Nucl. Mater. 98 (1981) 206-215.

[11] R.P. Turcotte, T.D. Chikalla, Radiat. Effects 19 (1973) 99-108.

[12] T.D. Chikalla, R.P. Turcotte, Radiat. Effects 19 (1973) 93-98.

[13] M. Kato, A. Komeno, H. Uno, H. Sugata, N. Nakae, K. Konashi, M. Kashimura, J. Nucl. Mater. 393 (2009) 134-140.

[14] D. Prieur, G. Pagliosa, J. Spino, R. Caciuffo, J. Somers, R. Eloirdi, J. Solid State Chem. 199 (2013) 334-337.

[15] M. Takano, M. Akabori, Y. Arai, J. Nucl. Mater. 414 (2011) 174-178.

[16] Z. Talip, T. Wiss, E.-A. Maugeri, J.-Y. Colle, P.-E. Raison, E. Gilabert, M. Ernstberger, D. Staicu, R.J.M. Konings, J. Eur. Ceram. Soc. 34 (2014) 1265-1277.

[17] A. Richard, H. Palancher, E. Castelier, J.-S. Micha, M. Gamaleri, G. Carlot, H. Rouquette, P. Goudeau, G. Martin, F. Rieutord, J. P. Piron, P. Garcia, J. Appl. Cryst. 45 (2012) 826-833.

[18] A. Richard, Ph.D. thesis, University of Poitiers, France (2012).

[19] A. Richard, E. Castelier, H. Palancher, J.S. Micha, H. Rouquette, A. Ambard, Ph. Garcia, Ph. Goudeau, Nucl. Instr. Meth. B., 326 (2014), 251 - 255.

[20] H. Palancher, P. Goudeau, A. Boulle, E. Castelier, F. Rieutord, V. Favre-Nicolin, N. Blanc, J. Fouet, C. Onofri, M. Ibrahim, Appl. Phys. Lett. Submitted.

[21] R.P. Turcotte, Pacific NothWest Laboratory report (1975) Conf 15-0915-21.

[22] W.J. Weber, J. Nucl. Mater. 114 (1983) 213-221.

[23] W.J. Weber, Radiat. Effects 83 (1984) 145-156.

[24] G. Leinders, T. Cardinaels, K. Binnemans, M. Verwerft, J. Nucl. Mater. 459 (2015) 135-142.

[25] G. Martin, G. Carlot, P. Desgardin, M. Vayer, C. Ramboz, T. Sauvage, P. Moretto, H. Khodja, P. Garcia, Defect and Diffusion Forum, 323-325(2012) 185-190.

[26] J.F. Ziegler, J.P. Biersack, M.D. Ziegler (1985). SRIM - The Stopping and Range of lons in Matter, http://www.srim.org.

[27] J. Soullard, J. Nucl. Mater. 135 (1985) 190-196.

[28] R. C. Belin, M. Strach, T. Truphémus, C. Guéneau, J.-C. Richaud, J. Rogez, J. Nucl. Mater. 465 (2015) 407-417.

[29] K. Wang, R.R. Reeber, Mater. Sci. Eng. Rep. 23 (1998) 101-137.

[30] P. Ruello, L. Desgranges, G. Baldinozzi, G. Calvarin, T. Hansen, G. Petot-Ervas, C. Petot, Journal of Physics and Chemistry of Solids 66 (2005) 823-831.

[31] H.M. Rietveld, J. Appl. Cryst. 2 (1969), 65-71. 
[32] J. Rodriguez-Carvajal, introduction to the program FullProf: Refinement of Crystal and Magnetic Structures from Powder and Single Crystal Data (2004).

[33] H. Palancher, R. Tucoulou, P. Bleuet, A. Bonnin, E. Welcomme, P. Cloetens, J. Appl. Cryst. 44, (2011) 1111-1119.

[34] I. Fritz, J. Appl. Phys. 47 (1976) 4353.

[35] A. Boulle and A. Debelle, J. Appl. Cryst. 43 (2010) 1046-1052.

[36] M. Souilah, A. Boulle, A. Debelle, J. Appl. Cryst. (2015) Submitted.

[37] E. Castelier, personal communication (2015).

[38] M. Ibrahim, Ph.D. thesis, University of Marne-La-Vallée, France (2015).

[39] E. Wait, cited in: B.T. Bradbury and B, R.T. Frost, Studies on Radiation Effects on Solids, G.J.

Dienes (ED.), Vol.2 (Gordon and Breach, New York, 1967), p.177.

[40] L. Desgranges, G. Guimbretière, P. Simon, F. Duval, A. Canizarès, R. Omnée, C. Jégou, R.

Caraballo, Nuclear Instruments and Methods in Physics Research Section B 327 (2014) 74-77.

[41] M. Ibrahim, E. Castelier, H. Palancher, M. Bornert, S. Carré, J.-S. Micha, J. Appl. Cryst. (2015). 48 990-999.

[42] C. Onofri, C. Sabathier, H. Palancher, G. Carlot, S. Miro, Y. Serruys, L. Desgranges, M.

Legros (2015) Nuclear Instruments and Methods in Physics Research Section B (2015), 10.1016/j.nimb.2015.08.091. 


\section{Acknowledgements}

Authors acknowledge the support of CEA and EDF within the frame of both PRECCI and COSTO projects. Moreover J.S. Micha and S. Tardif are thanked for their help during the HRXRD measurements performed on CRG BM32 beamline at the ESRF. H.P., C.O., R.B. and J-C.

R. (CEA) warmly thank R. Vauchy (CEA, DEN, DTEC) for his help during the last HT-XRD campaign. Finally, W.J. Weber, D. Prieur and M. Kato are sincerely acknowledged for providing their data reported in Figure 17. 


\section{List of tables}

Table 1: Conditions of both thermal treatment and XRD analysis for each $\mathrm{UO}_{2}$ polycrystals.

Table 2: Calculation of the initial linear free swelling in the $\mathrm{He}$ implanted $\mathrm{UO}_{2}$ polycrystals at room temperature prior to any thermal treatment. 


\section{List of figures}

Figure 1 : Calculated He concentration and damage profiles resulting from a $60 \mathrm{keV}^{4} \mathrm{He}^{+}$and $500 \mathrm{keV}$ ${ }^{3} \mathrm{He}^{+}$ion implantations into $\mathrm{UO}_{2}$ polycrystals (at a fluence of $10^{16} \mathrm{ions} / \mathrm{cm}^{2}$ ).

Figure 2 : Comparison between the penetration depths of 8 (black) and $17 \mathrm{keV}$ (red) X-ray beams in $\mathrm{UO}_{2}$ polycrystals in the $\theta / 2 \theta$ geometry and the thickness of the He implanted layers for two different ion energies (i.e. 60 and $500 \mathrm{keV}$ ). These penetration depths are plotted versus $\mathrm{K}$ values $\left(2 \times \frac{\sin (\theta)}{\lambda}\right)$ which are defined as the magnitude of scattering vectors.

Figure 3: XRD data measured in as-implanted ${ }^{3} \mathrm{He} 500 \mathrm{keV}$ polycrystals. (A-) Single grain characterization with a monochromatic X-ray beam for Sample X11 and (B-) macroscopic laboratory analysis using two $\mathrm{Cu}$ radiations $\left(\mathrm{Cu} \mathrm{K}_{\alpha 1}\right.$ and $\left.\mathrm{Cu} \mathrm{K}_{\alpha 2}\right)$ performed on Sample B1. Note that the layer B peak due to $\mathrm{Cu} \mathrm{K}_{\alpha 2}$ overlaps with $\mathrm{Cu} \mathrm{K}_{\alpha 1}$ peak and is therefore not indicated in B-. In both plots, XRD data have been shifted vertically for a better visualization.

Figure 4: Out-of-plane strain profile measured on HR-XRD data collected in the vicinity of the $\{220\}$ Bragg line in a $500 \mathrm{keV}{ }^{3} \mathrm{He}^{+}$implanted $\mathrm{UO}_{2}$ polycrystal. (A-) Comparison between the strain and damage profiles and (B-) agreement between measured and calculated data.

Figure 5: Evolution under the same isochronal thermal treatment performed under reducing atmosphere of the $\{220\}(A-)$ and $\{311\}$ (B-) Bragg lines measured in the same $\mathrm{UO}_{2}$ polycrystal implanted with $60 \mathrm{keV}$ He ions up to a $10^{16}$ ions $/ \mathrm{cm}^{2}$ final fluence (polycrystal written "Z1" in Table 1). The color code goes from white to black for low and high measured intensities respectively.

Figure 6: Maximal $\boldsymbol{\varepsilon}_{z z}$ strain component measured in the $60 \mathrm{keV}$ implanted layer as a function of time for 13 different temperatures up to $1100{ }^{\circ} \mathrm{C}$. (A-) $\{220\}$ and (B-) $\{311\}$ Bragg lines. Note the broken $\mathrm{X}$ axis. Polycrystal written "Z1" in Table 1.

Figure 7: Residual strain measured using 5 different Bragg lines in the $60 \mathrm{keV}$ implanted layer as a function of temperature after about 10000 s holding time (Polycrystal written "Z1" in Table 1).

Figure 8: Variation of the average strain relaxation (data point and smoothed curve) and of its derivative with respect to temperature. Case of the $60 \mathrm{keV}$ He implanted layer of the " $\mathrm{Z1}$ " $\mathrm{UO}_{2}$ polycrystal.

Figure 9: Evolution of the $\{222\} \cup \mathrm{O}_{2}$ Bragg line measured in the $\mathrm{X9}$ (A-) and $\mathrm{X} 1$ (B-) samples $\left(\mathrm{UO}_{2}\right.$ polycrystals implanted with $500 \mathrm{keV} H e$ ions) under reducing atmosphere and vacuum respectively.

Figure 10: Strains (A-) and strain recovery (B-) measured in the $\mathrm{X} 9$ polycrystal $\left(\mathrm{UO}_{2}\right.$ implanted with $500 \mathrm{keV} \mathrm{He}$ ions) samples under reducing atmosphere. These measurements are based on the analysis of the $\{222\} \cup \mathrm{O}_{2}$ Bragg line.

Figure 11: Strains (A-) and strain recovery (B-) measured in the $\mathrm{X} 1$ polycrystal $\left(\mathrm{UO}_{2}\right.$ implanted with $500 \mathrm{keV}$ He ions) under vacuum. These measurements are based on the analysis of the $\{222\} \mathrm{UO}_{2}$ Bragg line.

Figure 12: Residual strain measured in the $\mathrm{X} 2-\mathrm{X} 8, \mathrm{X} 10$ and $\mathrm{X} 12$ polycrystals $\left(\mathrm{UO}_{2}\right.$ implanted with 500 $\mathrm{keV} \mathrm{He}$ ) under isothermal annealing and vacuum. 
Figure 13: Variation of the $\{620\}$ Bragg line normalized measured intensity with time for four different isothermal treatments. Zoom over the first $80000 \mathrm{~s}$ of isothermal annealing.

Figure 14: Strain recovery measured in fifteen polycrystals $\left(\mathrm{UO}_{2}\right.$ implanted with $500 \mathrm{keV}$ He ions up to $10^{16} \mathrm{ion} / \mathrm{cm}^{2}$ ) annealed under vacuum.

Figure 15: Influence of He ion energy (A-) and annealing atmosphere (B-) on strain relaxation during isochronal annealing. Note that only polycrystals annealed under reducing atmosphere implanted with $500 \mathrm{keV}$ are taken into account in (A-) and (B-) respectively.

Figure 16: In-depth strain profile modification in the He implanted layer of polycrystals X9 (A-) and Z1 (B-) at 350 and $300{ }^{\circ} \mathrm{C}$ respectively.

Figure 17: Comparison between strain relaxation with temperature in the $\mathrm{Z1}$ polycrystal $\left(\mathrm{UO}_{2}\right.$ implanted $60 \mathrm{keV} \mathrm{He}$ ions) and $\mathrm{UO}_{2}$ single and poly crystals implanted with $5.5 \mathrm{MeV}$ He ions [22], MOX [13], $(\mathrm{Pu}, \mathrm{Cm}) \mathrm{O}_{2}$ [15], $\mathrm{U}_{0.8} \mathrm{Am}_{0.2} \mathrm{O}_{2-x}[14]$ self-irradiated pellets. Note that " $\mathrm{SC}^{\prime}$ and " $\mathrm{PC}$ " stand for single crystal and polycrystal respectively.

Figure 18: Comparison between residual strain and residual $\mathrm{He}$ in $\mathrm{UO}_{2}$ polycrystals $\mathrm{B} 2$ to $\mathrm{B} 6$. 


\begin{tabular}{|c|c|c|c|c|c|c|}
\hline $\begin{array}{l}\text { Sample } \\
\text { Number }\end{array}$ & $\begin{array}{l}\text { Energy of } \\
\text { the He ions } \\
\text { used for } \\
\text { implantation }\end{array}$ & $\begin{array}{c}\text { Type of } \\
\text { annealing }\end{array}$ & $\begin{array}{c}\text { Temperature } \\
\left({ }^{\circ} \mathrm{C}\right)\end{array}$ & Atmosphere & $\begin{array}{l}\text { Duration } \\
\text { (h) }\end{array}$ & $\begin{array}{c}\mathrm{XRD} \\
\text { analysis }\end{array}$ \\
\hline B1 [5] & 500 & None & & & & Ex-situ \\
\hline B2 [5] & 500 & Isothermal & 750 & Vacuum & 4 & Ex-situ \\
\hline B3 [5] & 500 & Isothermal & 800 & Vacuum & 4 & Ex-situ \\
\hline B5 [5] & 500 & Isothermal & 1000 & Vacuum & 0.5 & Ex-situ \\
\hline $\mathrm{B} 6$ [5] & 500 & Isothermal & 1100 & Vacuum & 0.25 & Ex-situ \\
\hline $\mathrm{X} 1$ & 500 & Isochronal & $\begin{array}{c}20-900 \text { (with } \\
50^{\circ} \mathrm{C} \\
\text { temperature } \\
\text { step) }\end{array}$ & vacuum & $\begin{array}{c}0.1 \mathrm{~h} \\
\text { holding } \\
\text { time/temp }\end{array}$ & In-situ \\
\hline $\mathrm{X} 2$ & 500 & Isothermal & 180 & vacuum & 64 & In-situ \\
\hline $\mathrm{X} 10$ & 500 & Isothermal & 250 & vacuum & 21 & In-situ \\
\hline $\mathrm{x3}$ & 500 & Isothermal & 300 & vacuum & 64 & In-situ \\
\hline $\mathrm{X} 4$ & 500 & Isothermal & 500 & vacuum & 17 & In-situ \\
\hline $\mathrm{X} 5$ & 500 & Isothermal & 620 & vacuum & 18 & In-situ \\
\hline $\mathrm{X} 12$ & 500 & Isothermal & 680 & vacuum & 3 & In-situ \\
\hline$x 6$ & 500 & Isothermal & 730 & vacuum & 21 & In-situ \\
\hline $\mathrm{X7}$ & 500 & Isothermal & 790 & vacuum & 0.5 & In-situ \\
\hline$x 8$ & 500 & Isothermal & 870 & vacuum & 17 & In-situ \\
\hline$x 9$ & 500 & Isochronal & $\begin{array}{c}20-1000 \\
\text { (with } 50^{\circ} \mathrm{C} \\
\text { temperature } \\
\text { step) }\end{array}$ & $\mathrm{He} / 5 \% \mathrm{H}_{2}$ & $\begin{array}{c}0.1 \mathrm{~h} \\
\text { holding } \\
\text { time/temp }\end{array}$ & In-situ \\
\hline $\mathrm{X} 11$ & 500 & None & & & & \\
\hline $\mathrm{Z1}$ & 60 & Isochronal & $\begin{array}{l}20-1100 \\
\text { (with } 50 \text { and } \\
100{ }^{\circ} \mathrm{C} \\
\text { temperature } \\
\text { step) }\end{array}$ & $\mathrm{He} / 5 \% \mathrm{H}_{2}$ & $\begin{array}{l}1 \mathrm{~h} \text { holding } \\
\text { time/temp }\end{array}$ & In-situ \\
\hline
\end{tabular}




\begin{tabular}{|c|c|c|c|c|c|c|c|c|c|}
\hline \multirow[t]{3}{*}{ Sample } & \multirow{3}{*}{$\begin{array}{l}\text { He ion } \\
\text { energy }\end{array}$} & \multicolumn{6}{|c|}{ Out-of-plane strain (\%) } & \multirow{2}{*}{\multicolumn{2}{|c|}{ Linear free swelling (\%) }} \\
\hline & & \multicolumn{2}{|c|}{$\boldsymbol{\varepsilon}_{z z}^{\mathbf{1 0 0}}$} & \multicolumn{2}{|c|}{$\varepsilon_{z z}^{110}$} & \multicolumn{2}{|c|}{$\varepsilon_{z z}^{111}$} & & \\
\hline & & $\begin{array}{c}\text { Layer } \\
\text { A }\end{array}$ & $\begin{array}{c}\text { Layer } \\
\text { B }\end{array}$ & $\begin{array}{c}\text { Layer } \\
\text { A }\end{array}$ & $\begin{array}{c}\text { Layer } \\
\text { B }\end{array}$ & $\begin{array}{c}\text { Layer } \\
\text { A }\end{array}$ & $\begin{array}{c}\text { Layer } \\
\text { B }\end{array}$ & Layer $\mathrm{A}$ & Layer B \\
\hline B1 [5] & 500 & 0.44 & 0.63 & 0.54 & 0.76 & 0.59 & 0.86 & $\begin{array}{c}0.28 \pm \\
0.01\end{array}$ & $0.40 \pm 0.01$ \\
\hline $\mathrm{X} 1$ & 500 & 0.43 & 0.69 & 0.50 & 0.85 & 0.61 & 0.93 & $\begin{array}{c}0.28 \pm \\
0.02\end{array}$ & $0.43 \pm 0.01$ \\
\hline $\mathrm{X} 2$ & 500 & 0.50 & 0.70 & 0.59 & 0.85 & 0.64 & 0.92 & $\begin{array}{c}0.30 \pm \\
0.02\end{array}$ & $0.43 \pm 0.02$ \\
\hline$x 3$ & 500 & 0.50 & 0.65 & 0.67 & 0.90 & 0.71 & 0.96 & $\begin{array}{c}0.33 \pm \\
0.01\end{array}$ & $0.44 \pm 0.01$ \\
\hline $\mathrm{X} 4$ & 500 & 0.47 & 0.65 & 0.64 & 0.87 & 0.67 & 0.92 & $\begin{array}{c}0.28 \pm \\
0.01\end{array}$ & $0.42 \pm 0.01$ \\
\hline $\mathrm{X} 5$ & 500 & 0.42 & 0.63 & 0.54 & 0.83 & 0.62 & 0.92 & $\begin{array}{c}0.27 \pm \\
0.01\end{array}$ & $0.42 \pm 0.01$ \\
\hline $\mathrm{x} 6$ & 500 & 0.46 & 0.67 & 0.53 & 0.84 & 0.64 & 0.91 & $\begin{array}{c}0.29 \pm \\
0.02\end{array}$ & $0.43 \pm 0.01$ \\
\hline $\mathrm{X} 7$ & 500 & 0.44 & 0.68 & 0.56 & 0.85 & 0.63 & 0.93 & $\begin{array}{c}0.29 \pm \\
0.01\end{array}$ & $0.43 \pm 0.01$ \\
\hline $\mathrm{x} 8$ & 500 & 0.38 & 0.65 & 0.40 & 0.83 & 0.55 & 0.91 & $\begin{array}{c}0.23 \pm \\
0.03\end{array}$ & $0.42 \pm 0.00$ \\
\hline$x 9$ & 500 & 0.42 & 0.67 & 0.54 & 0.84 & 0.61 & 0.92 & $\begin{array}{c}0.27 \pm \\
0.01 \\
\end{array}$ & $0.43 \pm 0.01$ \\
\hline $\mathrm{X} 10$ & 500 & 0.49 & 0.65 & 0.69 & 0.90 & 0.68 & 0.95 & $\begin{array}{c}0.32 \pm \\
0.02\end{array}$ & $0.44 \pm 0.01$ \\
\hline $\mathrm{X} 11$ & 500 & 0.47 & 0.66 & 0.61 & 0.88 & 0.63 & 0.94 & $\begin{array}{c}0.31 \pm \\
0.01 \\
\end{array}$ & $0.45 \pm 0.02$ \\
\hline \multicolumn{2}{|c|}{ Average } & $\begin{array}{c}0.45 \\
\pm 0.04 \\
\end{array}$ & $\begin{array}{c}0.66 \\
\pm 0.02 \\
\end{array}$ & $\begin{array}{l}0.57 \\
\pm 0.08 \\
\end{array}$ & $\begin{array}{l}0.85 \\
\pm 0.04 \\
\end{array}$ & $\begin{array}{c}0.63 \\
\pm 0.04 \\
\end{array}$ & $\begin{array}{c}0.92 \\
\pm 0.02 \\
\end{array}$ & $\begin{array}{c}0.30 \pm \\
0.01\end{array}$ & $0.43 \pm 0.01$ \\
\hline $\mathrm{Z1}$ & 60 & \multicolumn{2}{|c|}{0.70} & \multicolumn{2}{|c|}{0.91} & \multicolumn{2}{|c|}{1.00} & \multicolumn{2}{|c|}{$0.46 \pm 0.01$} \\
\hline
\end{tabular}




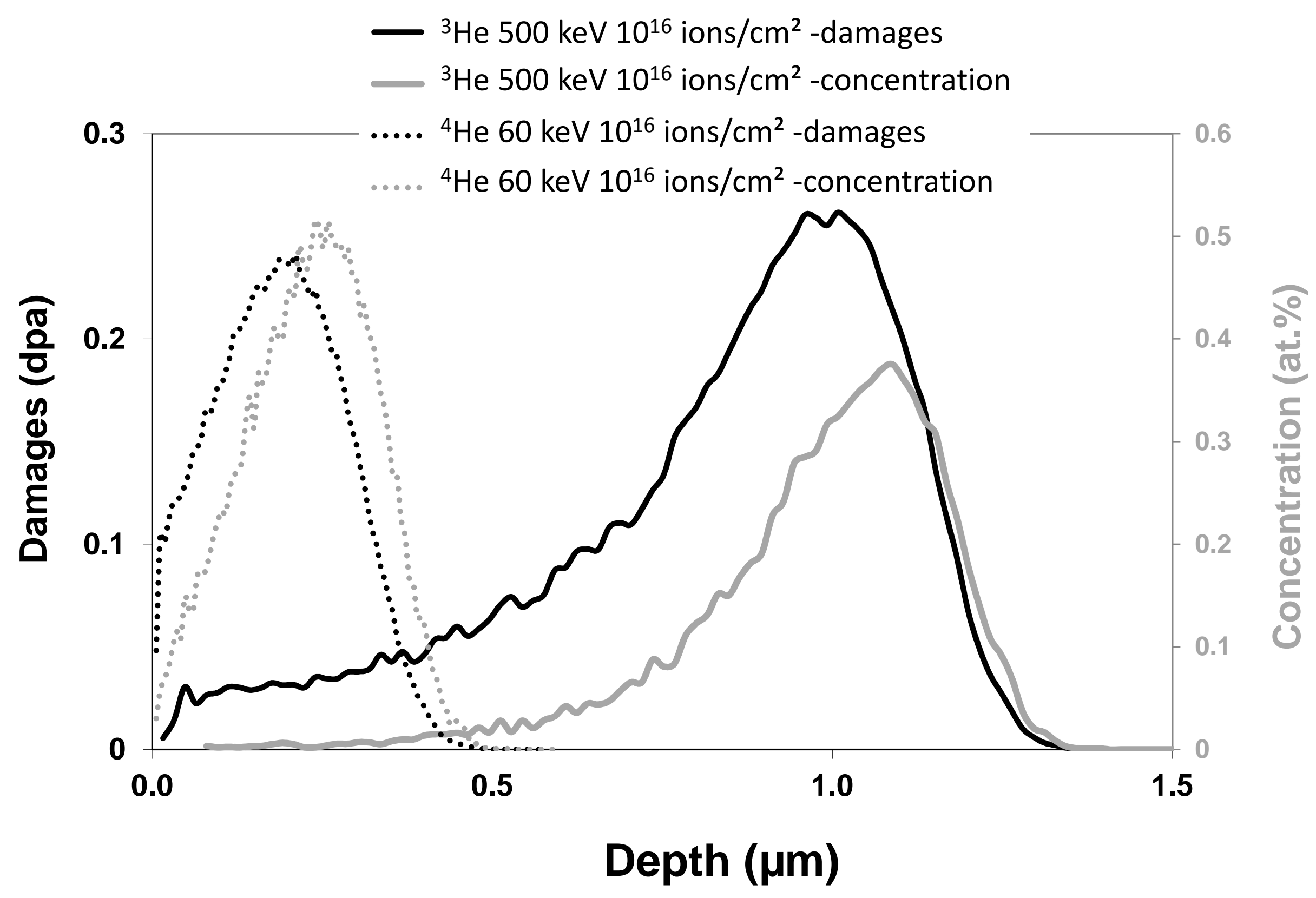




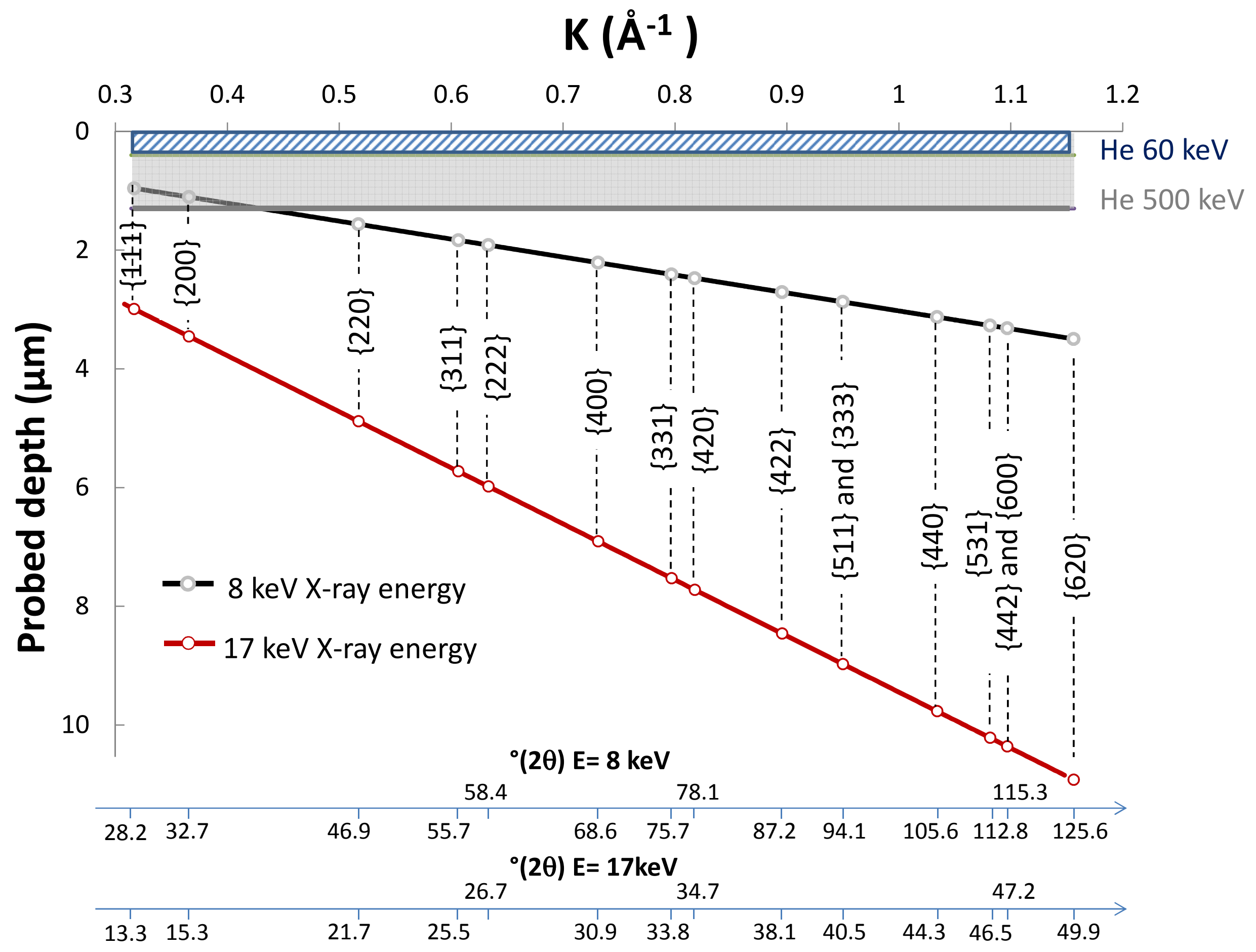



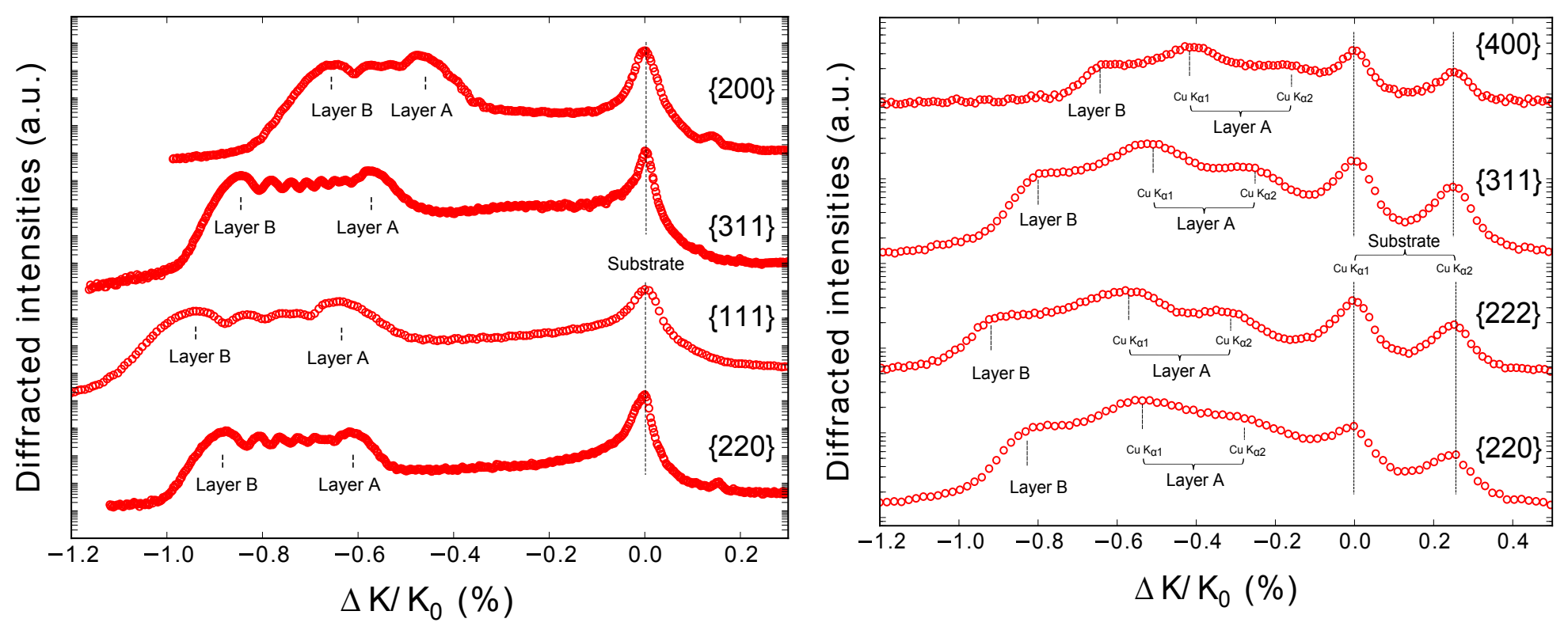
A-

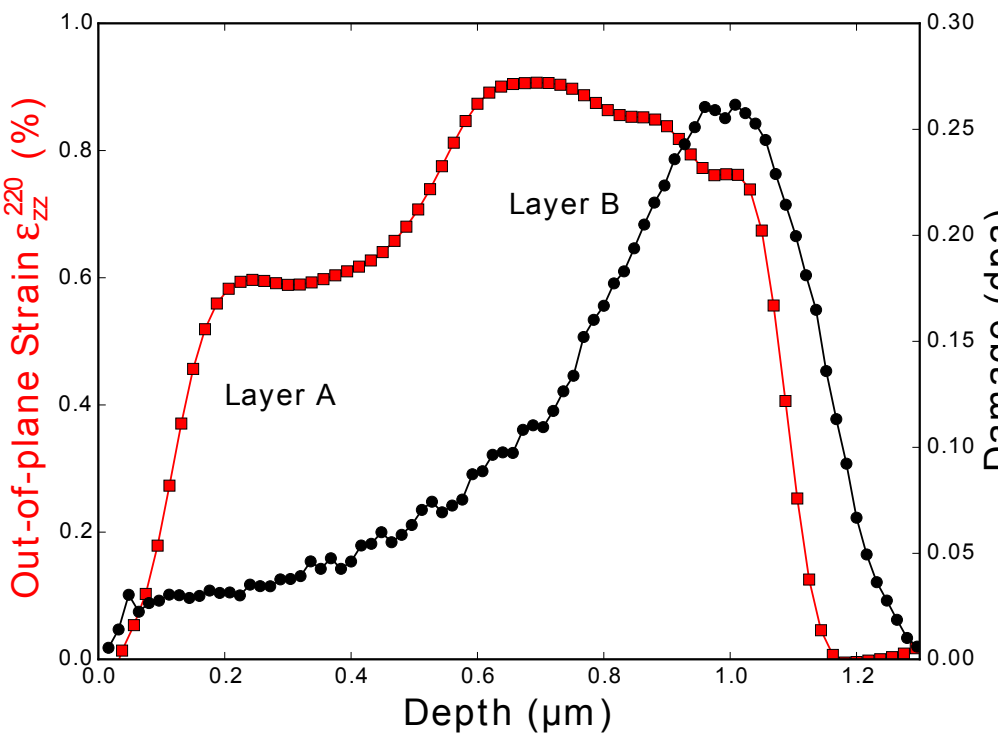

B-

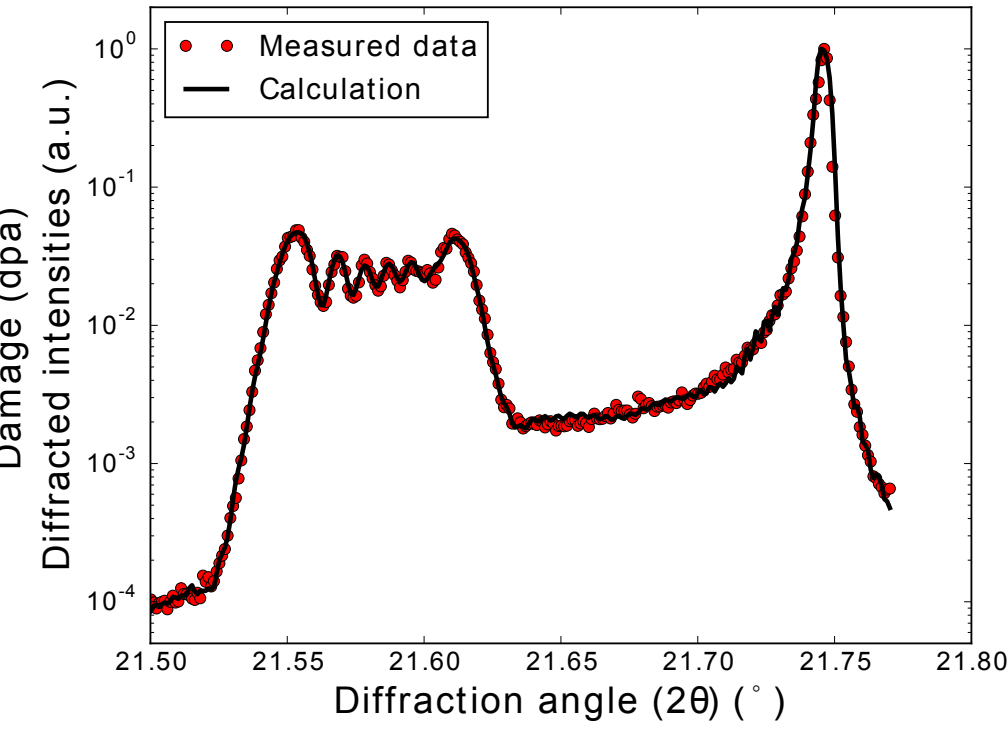


A-

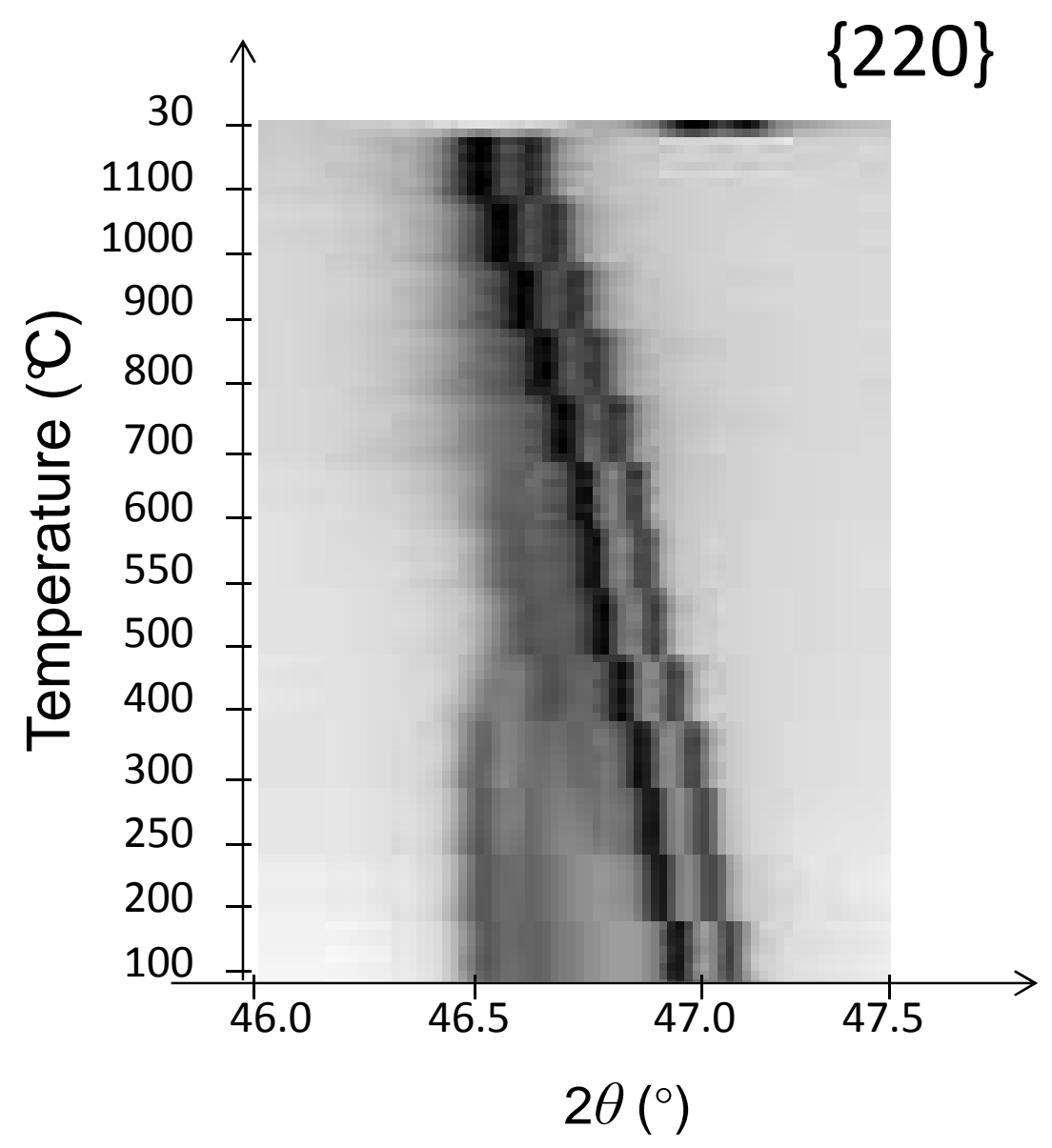

B-

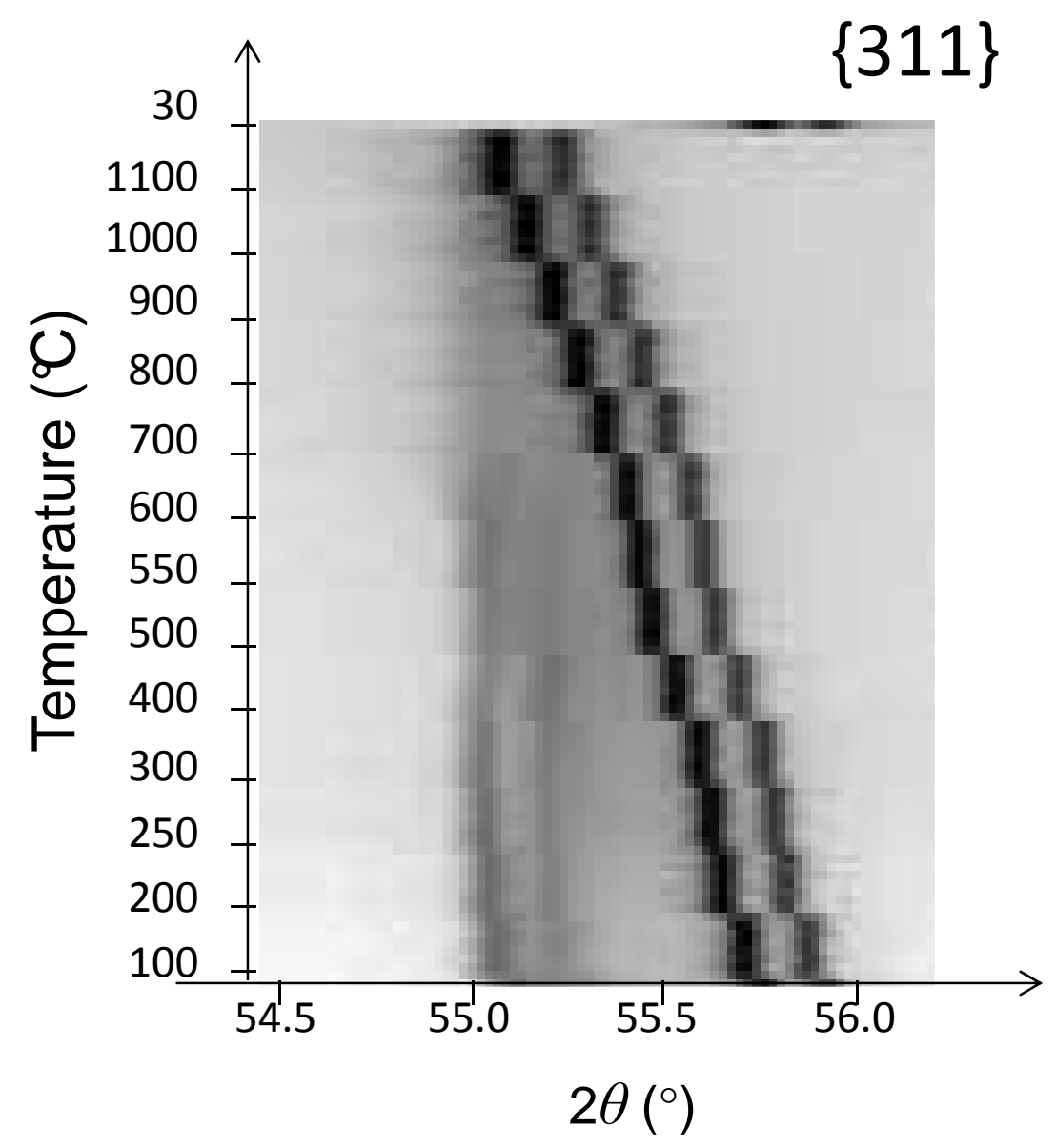




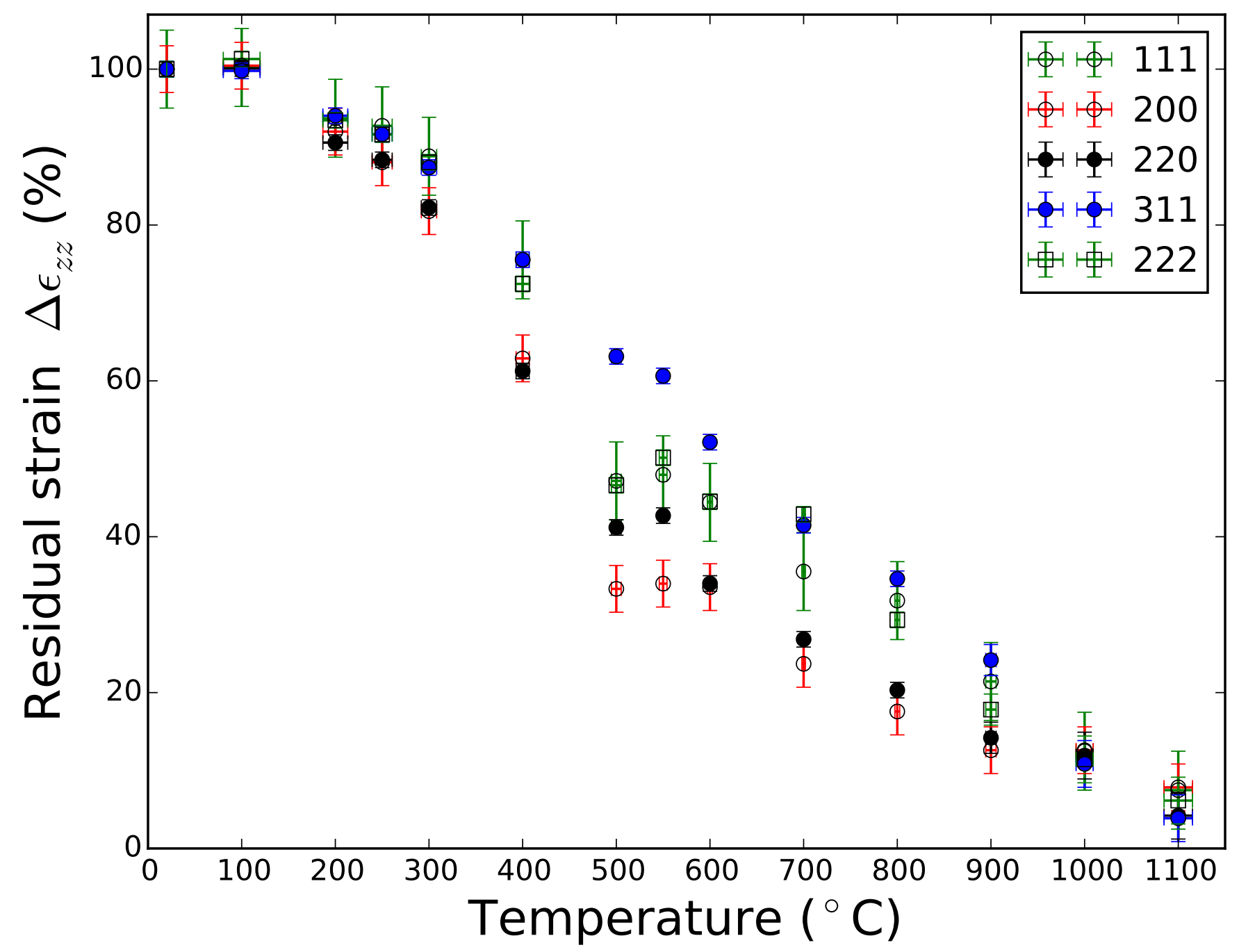




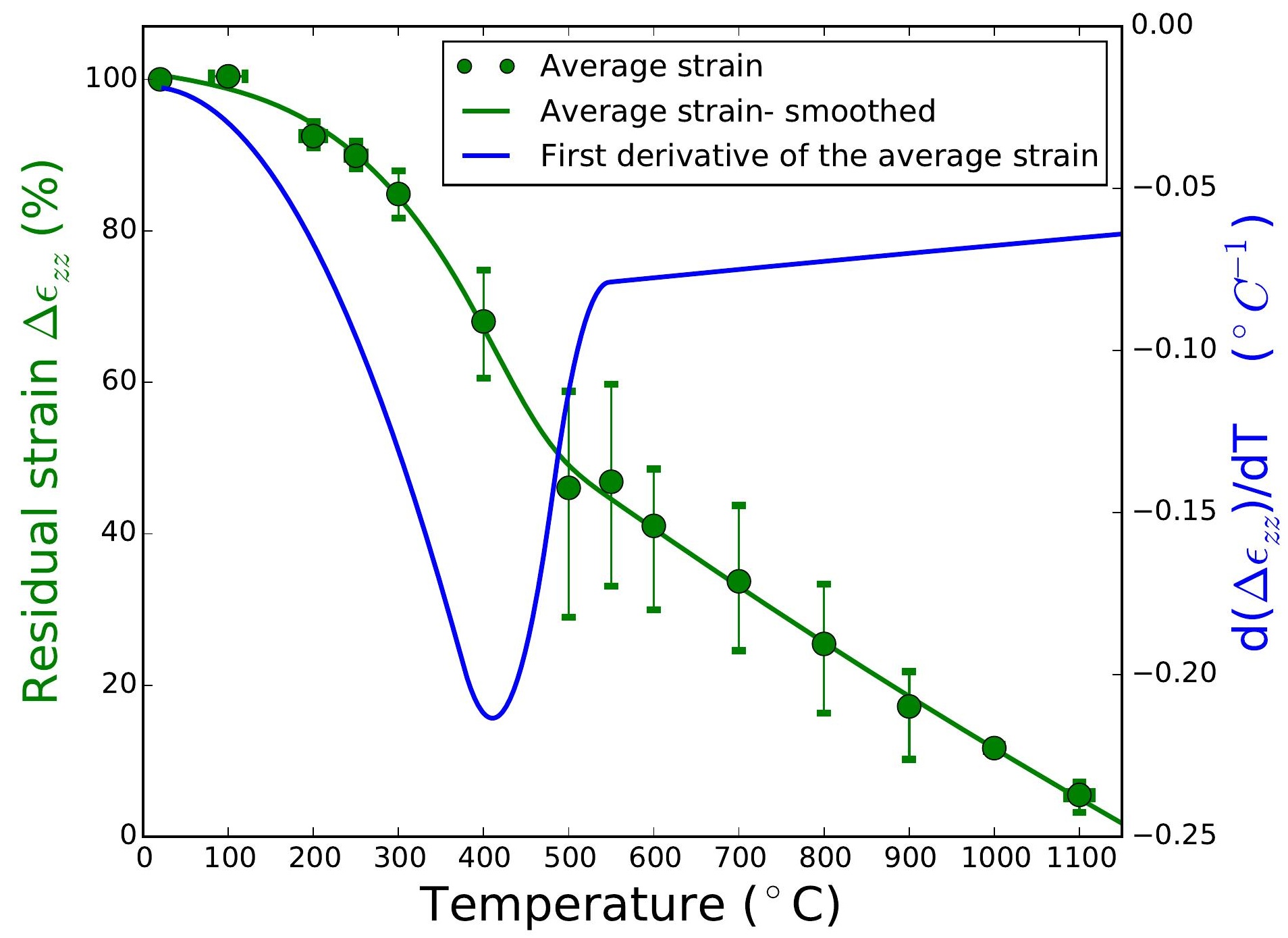



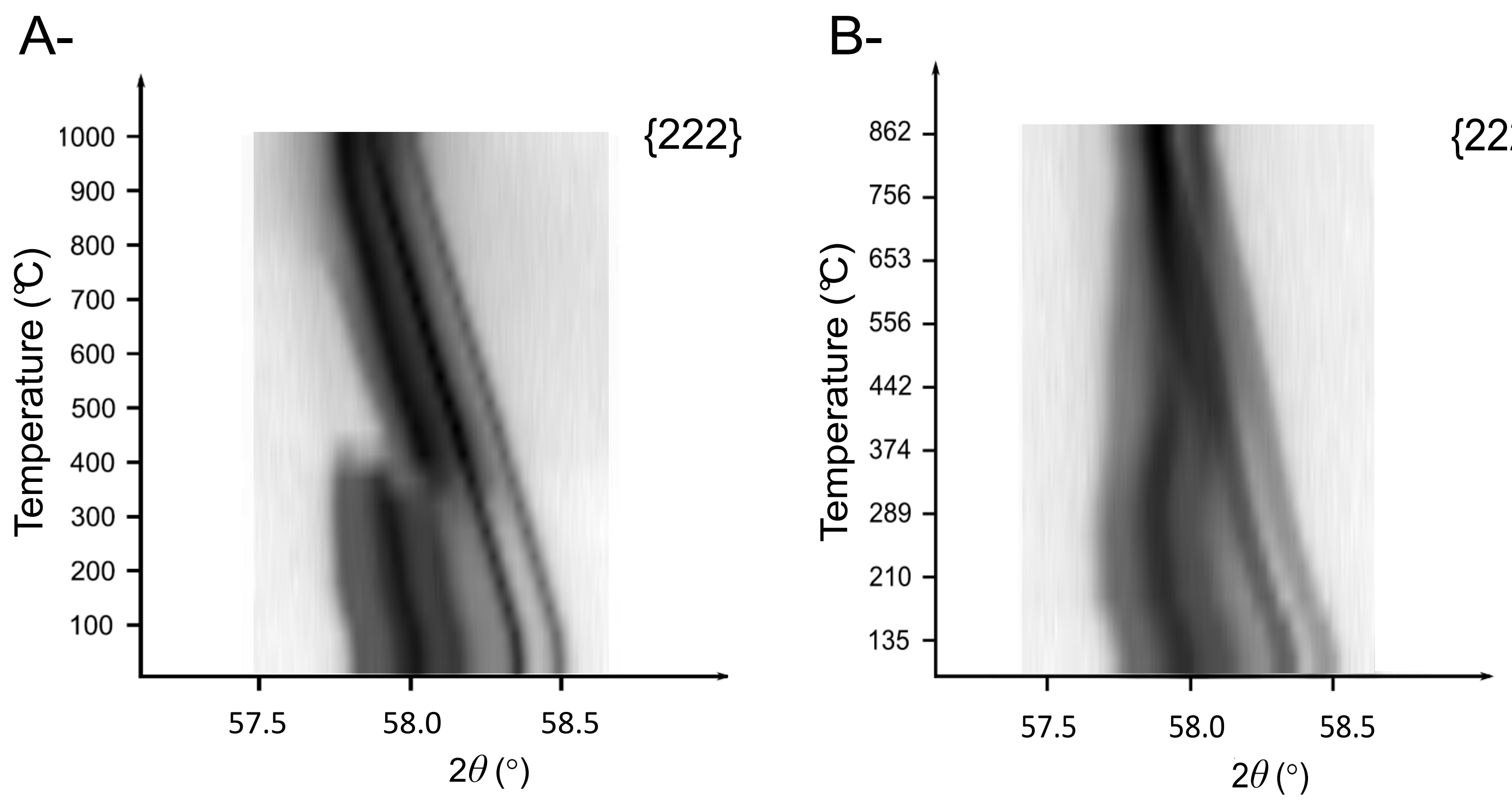


\section{Figure}

A-

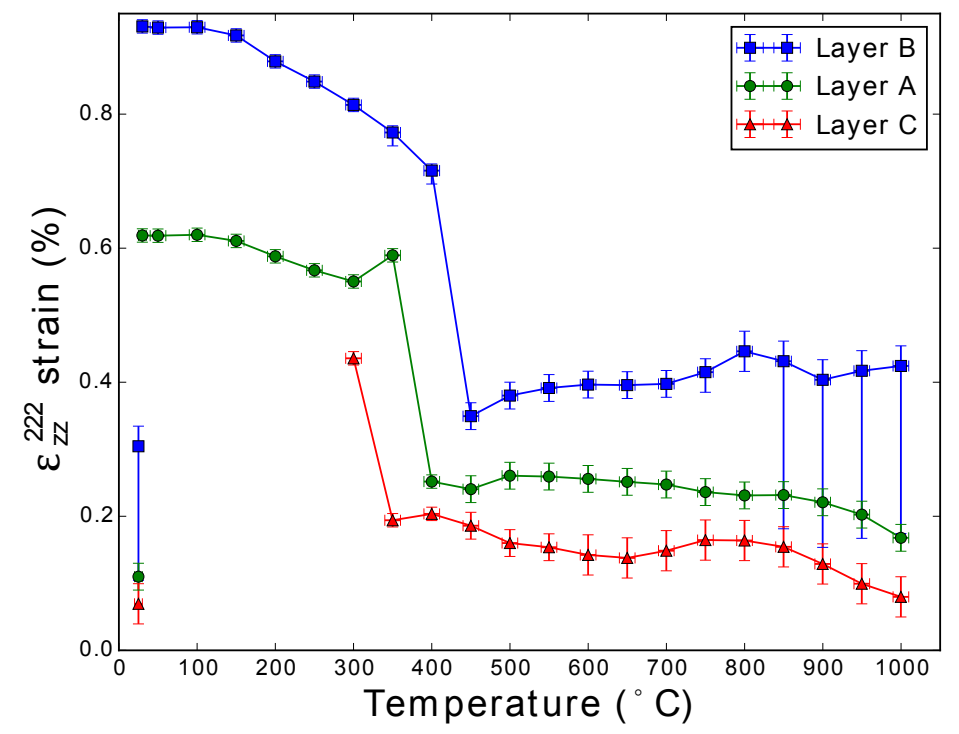

B-

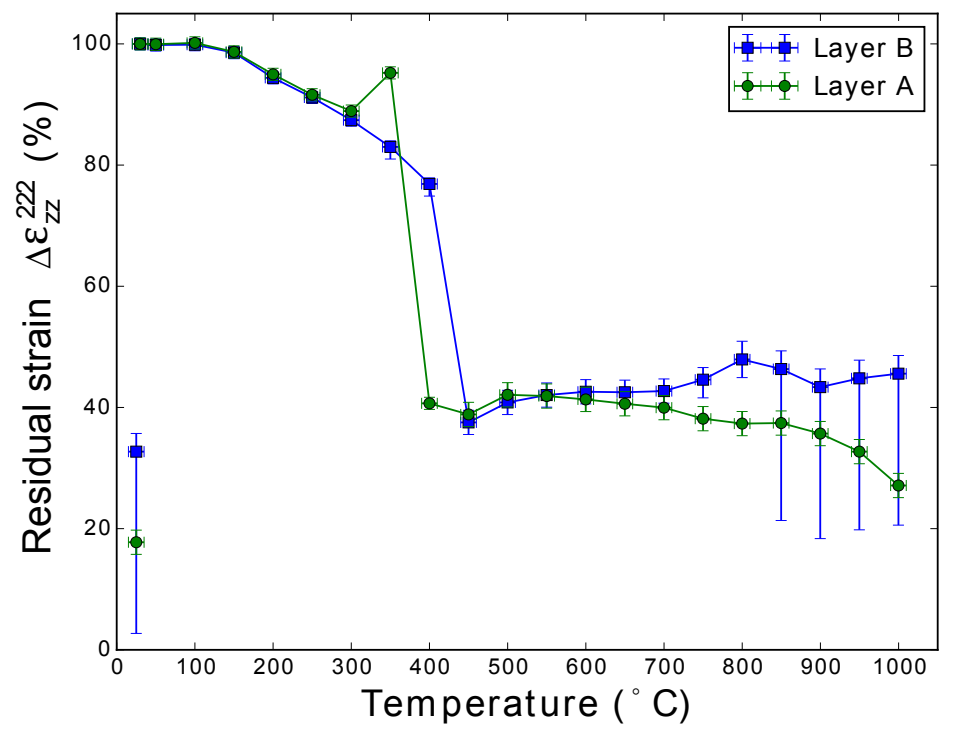




\section{Figure}

A-

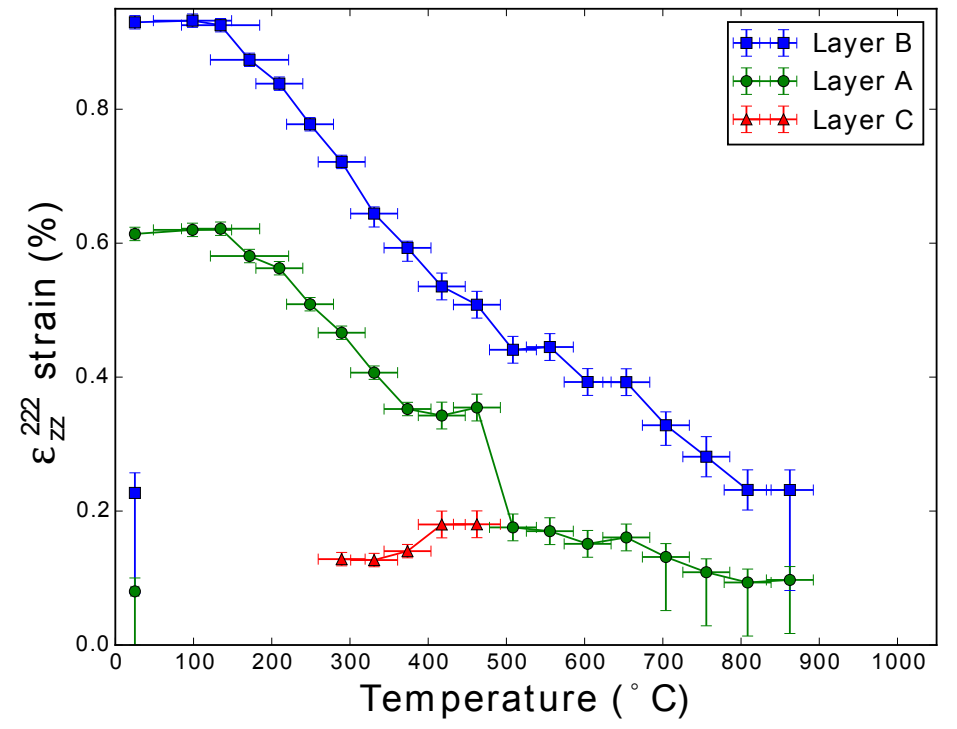

B-

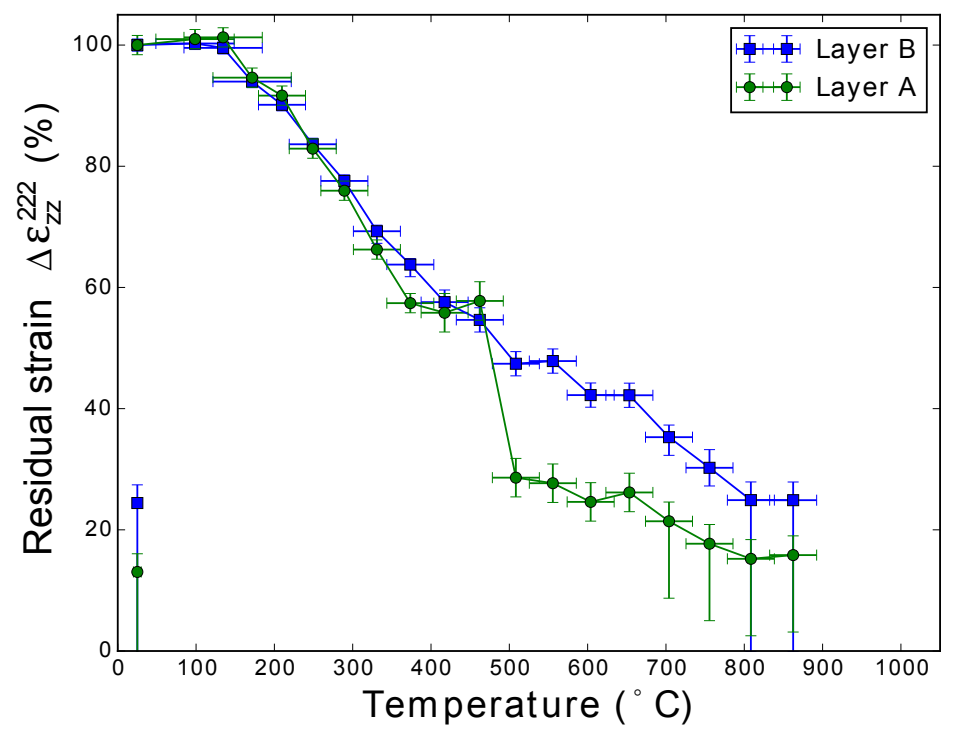


A-

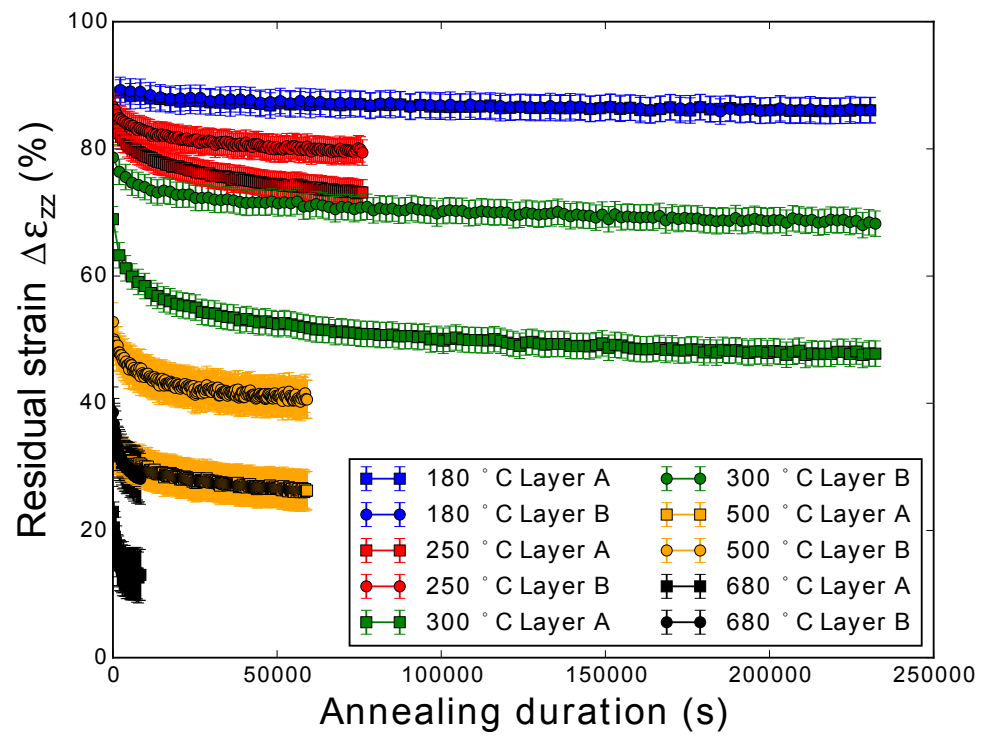

B-

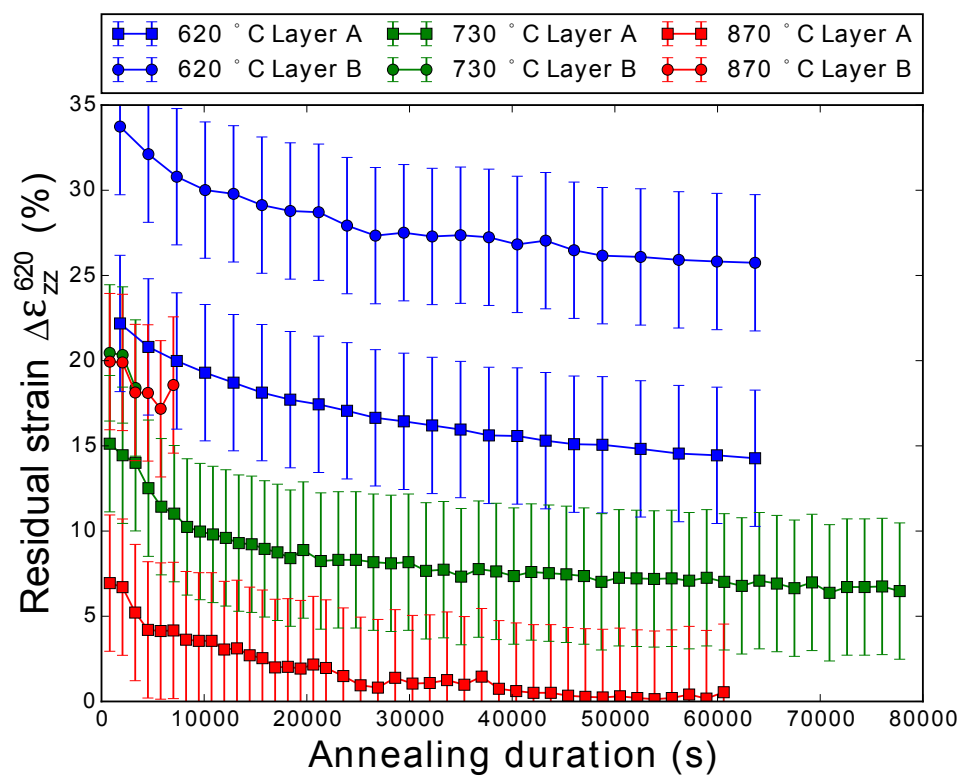




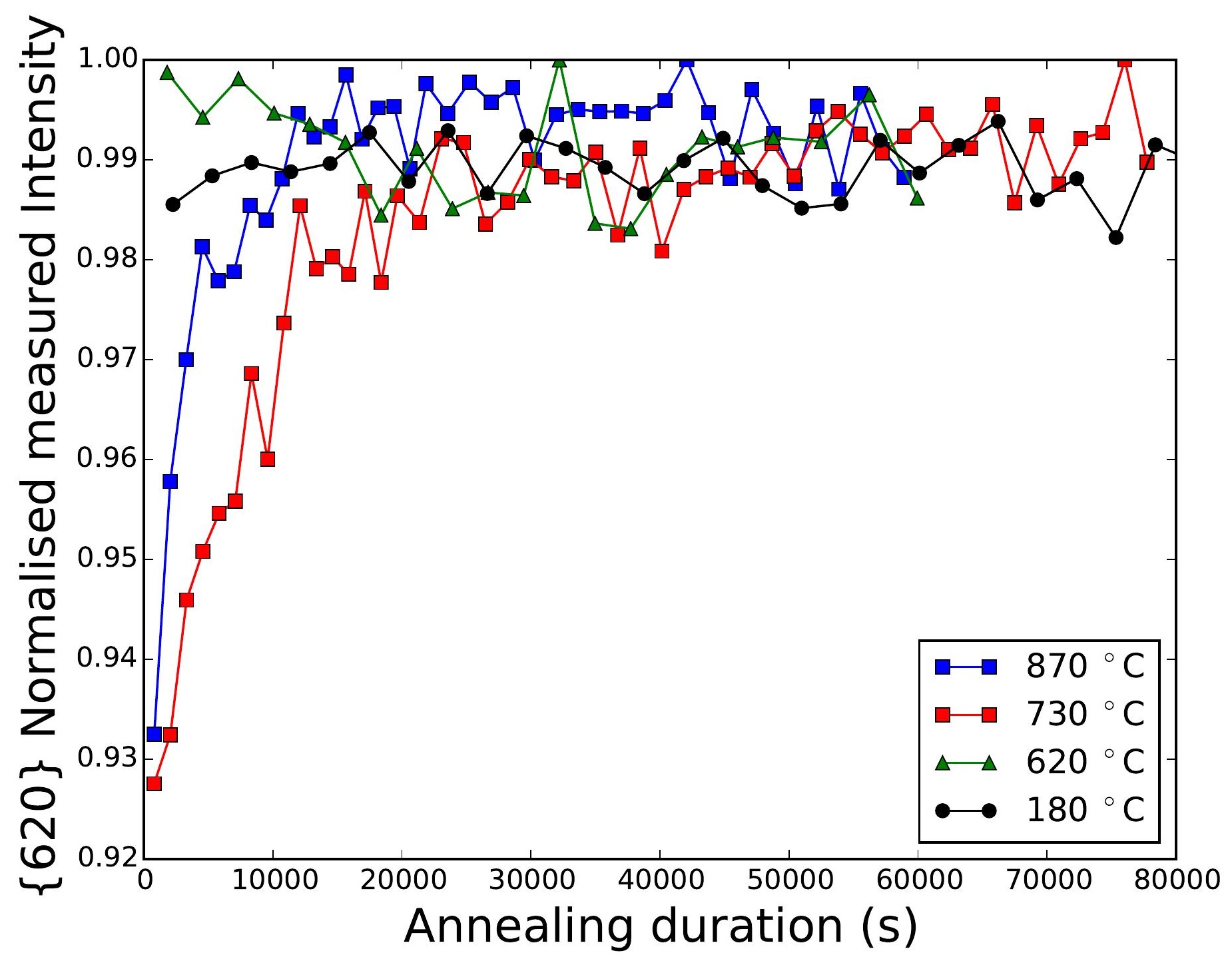




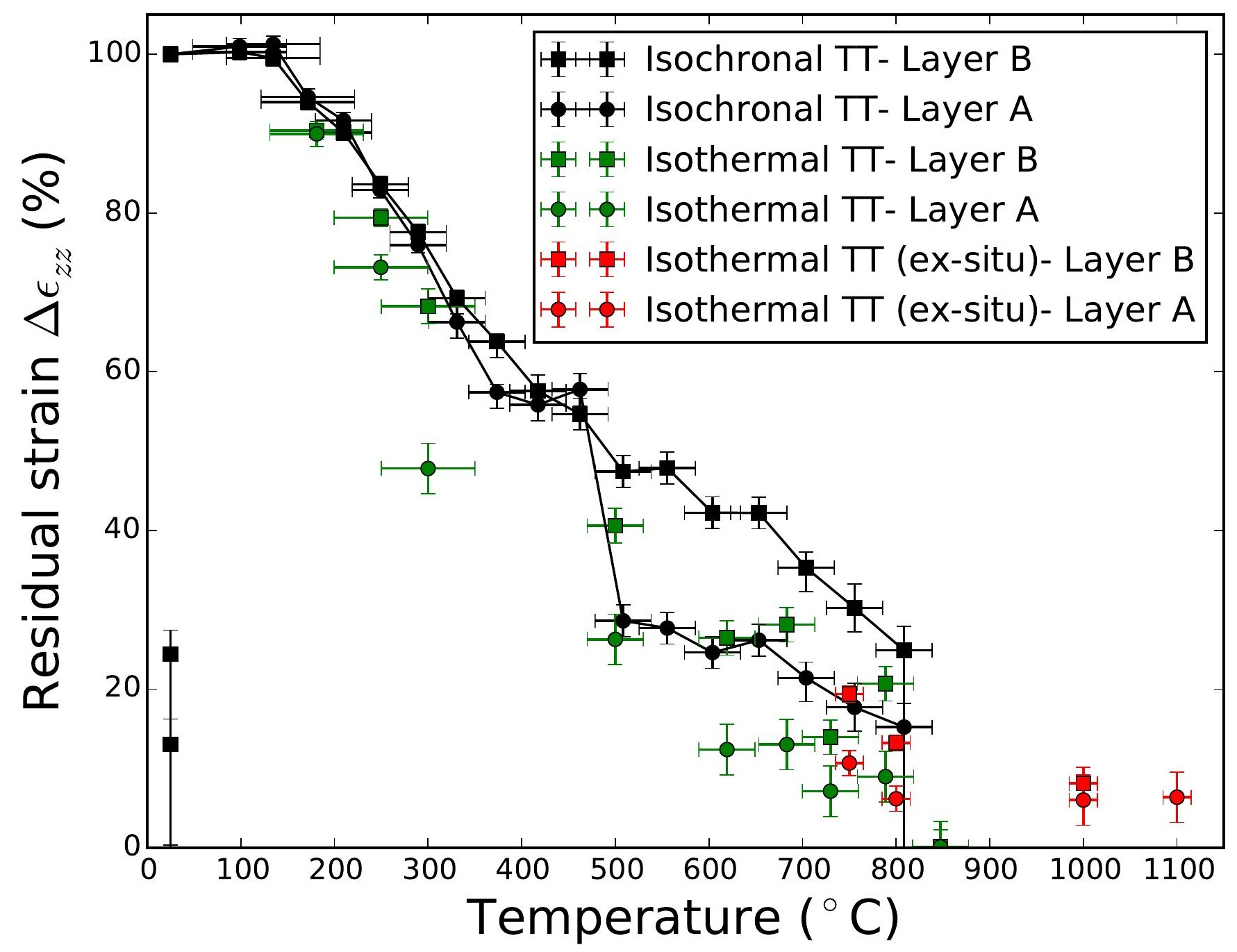




\section{Figure}

A-

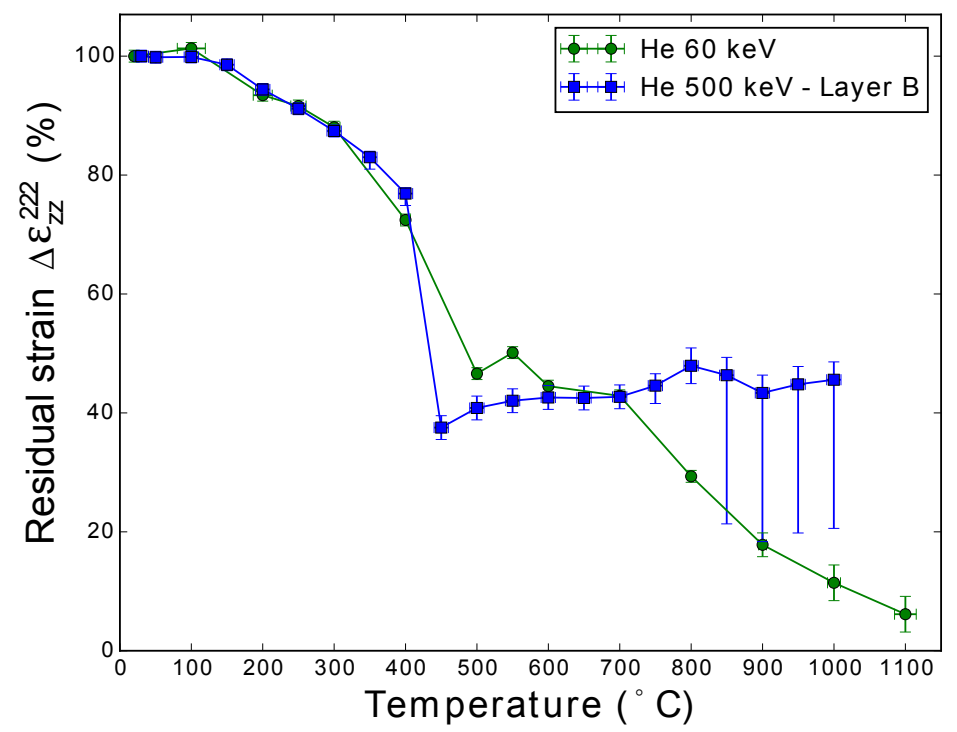

B-

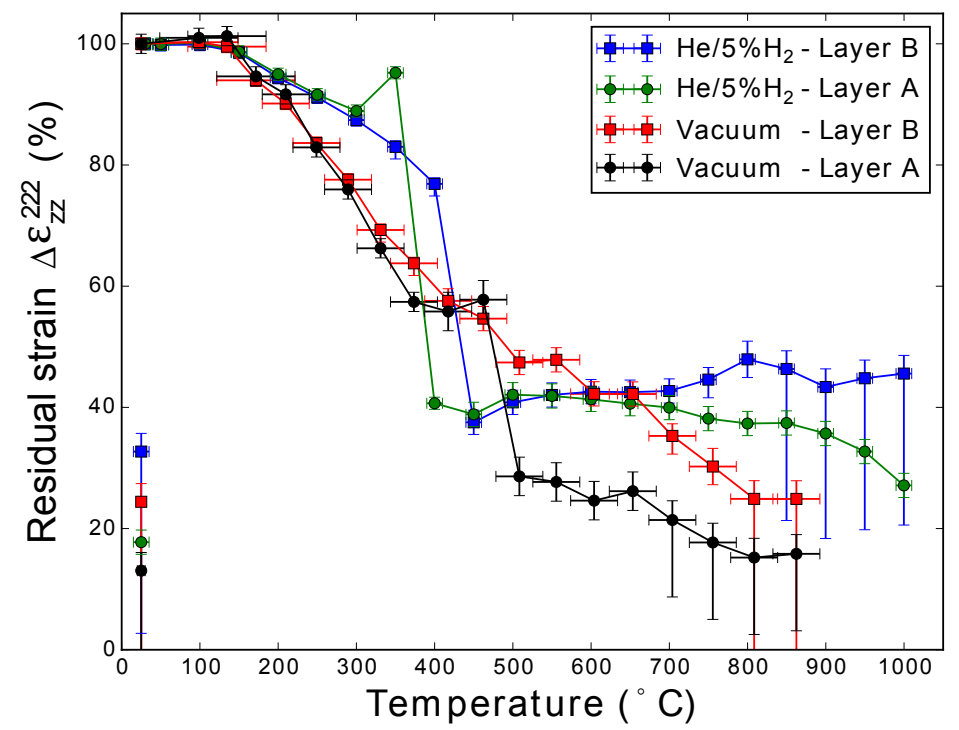



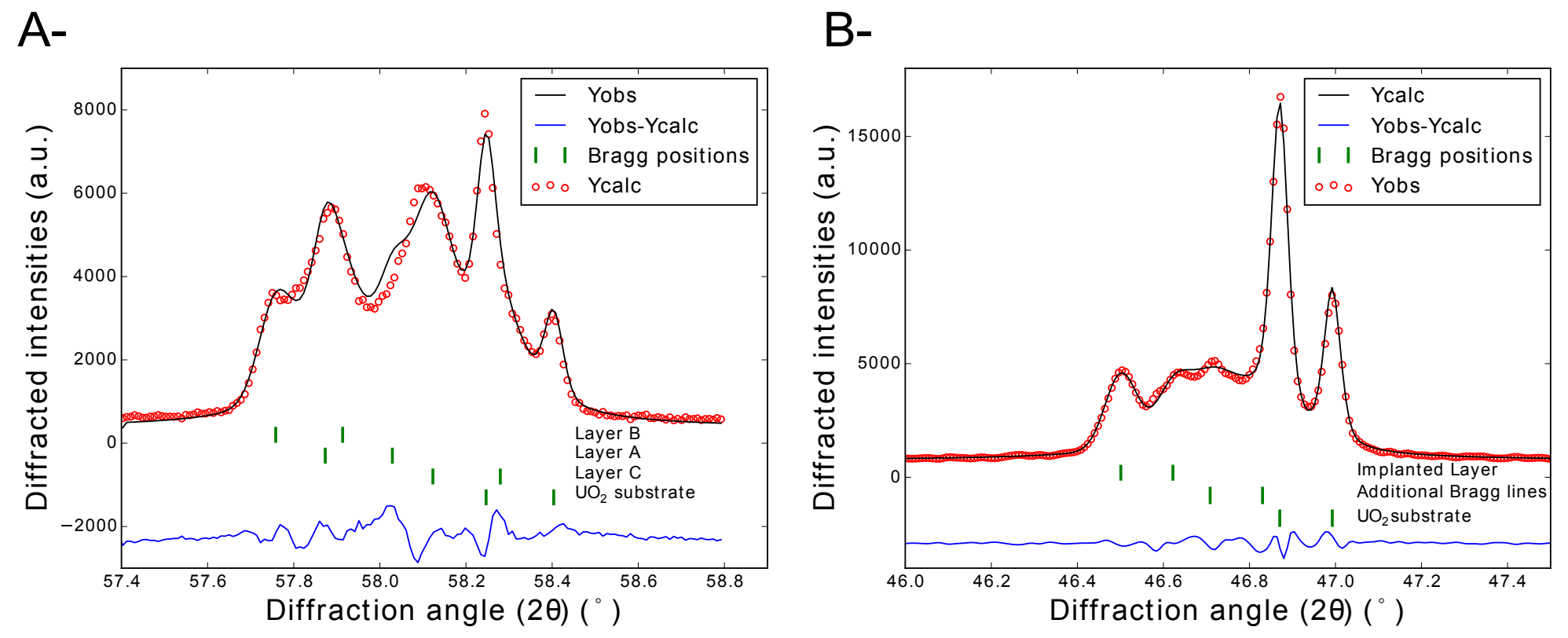


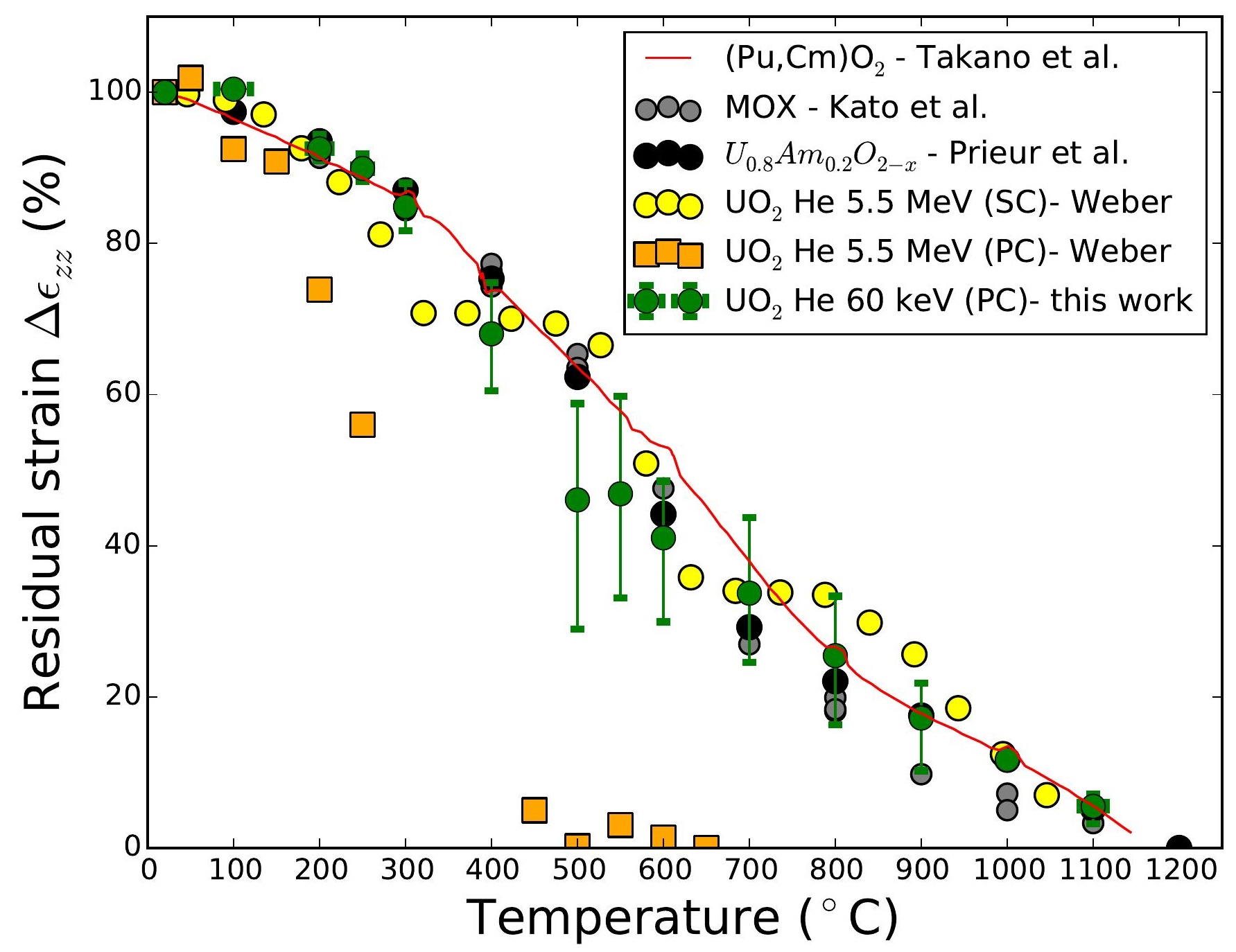




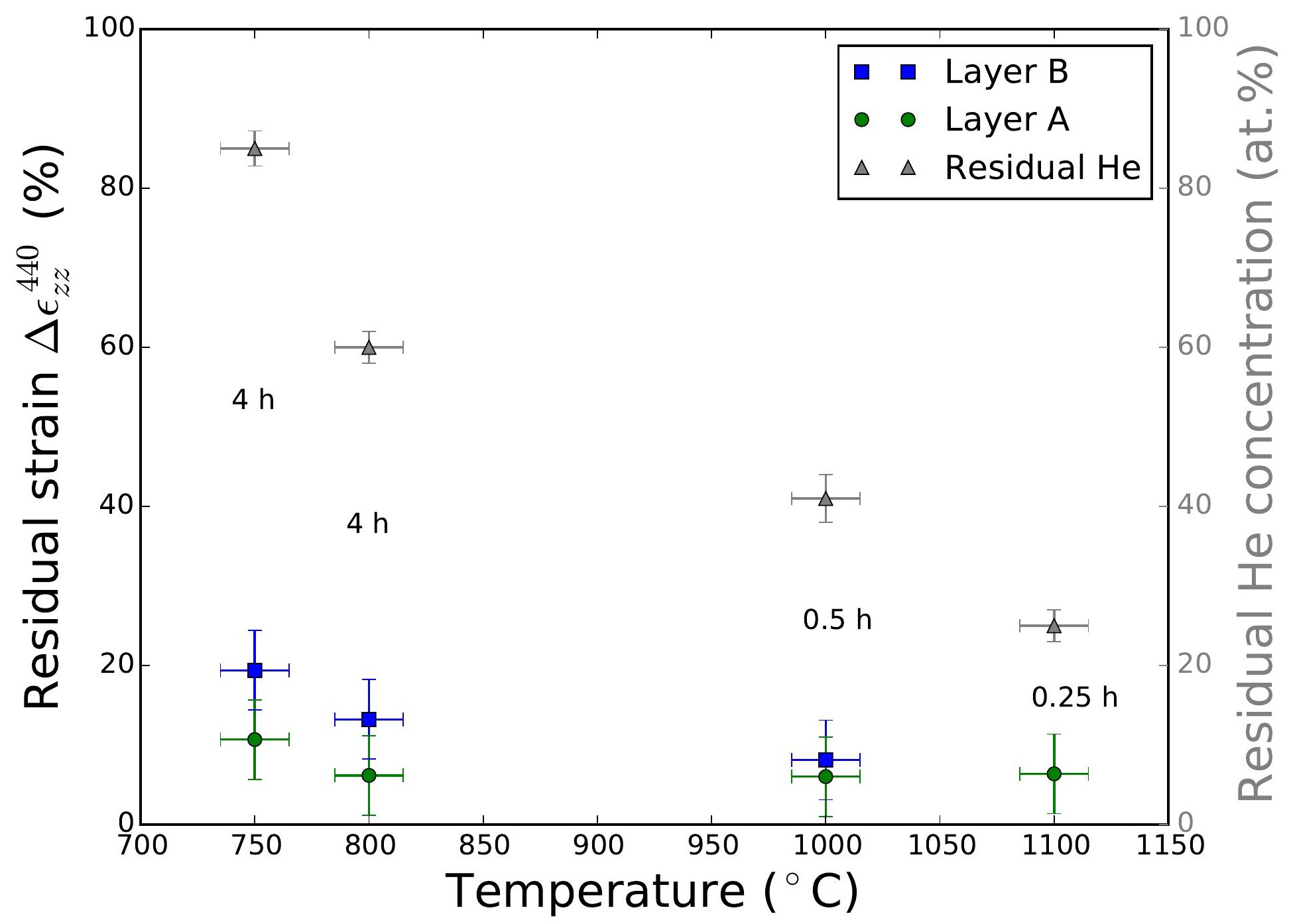

